\title{
A missense KCNQ1 Mutation Impairs Insulin Secretion in Neonatal Diabetes
}

Zhimin Zhou1\#, Maolian Gong1\#, Amit Pande1, Ulrike Lisewski², Torsten Röpke², Bettina Purfürst ${ }^{1}$, Lei liang ${ }^{3}$, Shiqi Jia ${ }^{4}$, Sebastian Frühler ${ }^{1}$, Anca Margineanu1 ${ }^{1}$, Chun Zeng5,6, Han Zhu'5,6, Peter Kühnen ${ }^{9}$, Semik Khodaverdi7, Winfried Krill7, Wei Chen ${ }^{8}$, Maike Sander ${ }^{5,6,{ }^{*}}$, Klemens Raile ${ }^{9, *}$, Zsuzsanna Izsvak1,*

${ }^{1}$ Max Delbrück Center for Molecular Medicine in the Helmholtz Association (MDC), 13125 Berlin, Germany.

2Experimental and Clinical Research Center (ECRC) of the MDC and Charite Berlin, 13125 Berlin, Germany.

3Department of Pediatrics, Anhui Provincial Children's Hospital, 23000 Hefei, China 4The First Affiliated Hospital of Jinan University, 510000 Guangzhou, China.

5Department of Cellular and Molecular Medicine, University of California San Diego, La Jolla, CA, USA.

6Department of Pediatrics, University of California San Diego, La Jolla, CA 92037 , USA.

7Department of Pediatrics, Klinikum Hanau, 63450 Hanau, Germany.

${ }^{8}$ Department of Biology, Southern University of Science and Technology, 518000 Shenzhen, China.

${ }^{9}$ Charité, Universitätsmedizin Berlin, Virchow-Klinikum, 13125 Berlin, Germany

\#These authors contributed equally to this work.

* Correspondence e-mail: zizsvak@mdc-berlin.de (Zsuzsanna Izsvak); klemens.raile@charite.de (Klemens Raile); masander@health.ucsd.edu (Maike Sander). 


\section{Abstract}

$\mathrm{KCNQ} 1 / \mathrm{Kv} 7$ is a voltage-gated $\mathrm{K}^{+}$channel that regulates heart rhythm, glucose and salt homeostasis. Mutations of $K C N Q 1$ are primarily associated with long-QT syndrome and type 2 diabetes; however, thus far KCNQ1 mutations have not been associated with monogenetic diabetes. Here, we identified a homozygous KCNQ1 missense mutation (R397W) in an individual with permanent neonatal diabetes (PND). To identify the mechanisms that link the mutation to the disease, we introduced the mutation into human embryonic stem cells (hESCs), and used them to derived pancreatic $\beta$-like cells (hESC- $\beta$ cell). In early $\beta$-like cells, we observed atypical membrane electrical activity, increased levels of cytoplasmic $\mathrm{Ca}^{2+}$, and a hypersecretion of insulin. Upon extended culture, their insulin secretion decreased and the number of apoptotic cells increased, resulting in a reduction in the numbers of $\beta$-like cells. Late-stage $\beta$-like cells exhibited a decrease in the expression of metabolic genes, e.g. HNF4a, PDX1 and GLUT1, providing a possible mechanism for $\beta$-cell dysfunction. Our study identifies $K C N Q 1$ as a novel candidate gene of monogenetic diabetes and shows that $K C N Q 1$ regulates $\beta$-cell function and survival.

Keywords GLUT1/ hESC- $\beta$ cell / insulin secretion / KCNQ1/Kv7 channel / permanent neonatal diabetes 


\section{Introduction}

The potassium Voltage-Gated Channel Subfamily Q 1 (KCNQ1) channel plays physiological roles in the cardiovascular system, intestine and pancreas (Neyroud, Tesson et al., 1997, Schroeder, Waldegger et al., 2000, Waldegger, Fakler et al., 1999, Kottgen, Hoefer et al., 1999), where it regulates several essential processes, including repolarization of cardiomyocytes, vasodilatation and secretion (Barhanin, Lesage et al., 1996, Chadha, Zunke et al., 2012, Jepps, Chadha et al., 2011, Zeng, Guo et al., 2016). The KCNQ1/Kv7 channel induces voltage-dependent current by rapidly activating and slowly deactivating potassium-selective outward current (Chouabe, Neyroud et al., 1997, Sanguinetti, Curran et al., 1996, Sachyani, Dvir et al., 2014). Hereditary mutations of $K C N Q 1$ are primarily associated with cardiovascular pathologies (e.g. long QT syndrome 1, short QT syndrome 2, familial atrial fibrillation or Jervell and Lange-Nielsen syndrome) (Valente, Sparago et al., 2019, Chen, Xu et al., 2003, Bellocq, van Ginneken et al., 2004). KCNQ1 is also a strong candidate for conferring susceptibility to type 2 diabetes (T2D) (MacDonald \& Wheeler, 2003, Unoki, Takahashi et al., 2008, Yasuda, Miyake et al., 2008, Chiou, Zeng et al., 2021). So far, however, mutations in $K C N Q 1$ have not been associated with monogenic diabetes.

Roughly $2-6 \%$ of all patients with diabetes have a hereditary monogenic form that arises from one or more gene mutation(s) in a single gene (Thomas, Brackenridge et al., 2016, Cho, Shaw et al., 2018). While MODY summarizes the majority of hereditary monogenic diabetes cases (most common mutations in glucokinase (GCK), hepatocyte nuclear factors (HNF) $1 \alpha, 4 \alpha, 1 \beta$ ) (Sanyoura, Philipson et al., 2018), NDM is much rarer, accounted only about $0.012 \%$ of all live births (Grulich-Henn et al., 2010). In contrast to maturity-onset diabetes (MODY), which develops in adolescence or early adulthood (Hattersley \& Patel, 2017), neonatal diabetes mellitus (NDM) is usually diagnosed within the first 180 days of life and is more severe (Grulich-Henn, Wagner et al., 2010). Patients with transient or permanent NDM exhibit severe $\beta$-cell dysfunction accompanied by a reduction in islet cell mass and sometimes even pancreas aplasia (Polak \& Cave, 2007, Aguilar-Bryan \& Bryan, 2008). If insulin is 
absent during fetal development, the fetus could fail to thrive after birth. Even in milder cases, neonates with NDM are marked to suffer from life-long acute hyperglycemia and life-threatening dehydration (Polak \& Cave, 2007, Mohora \& Stoicescu, 2016).

So far NDM has been associated with mutations in the $A B C C 8, K C N J 11$, and INS genes. Here, we report a permanent NDM (PND) patient with a homozygous KCNQ1 mutation (C1189T). The mutated $\mathrm{K}_{\mathrm{v}} 7$ channel protein $K C N Q 1$, contributing to permanent NDM is especially interesting. The hereditary mutations of $K C N Q 1$ are primarily associated with cardiovascular and not from metabolic disorders. Although several lines of evidence supports an association between $K C N Q 1$ and the regulation of insulin secretion (MacDonald \& Wheeler, 2003, Unoki et al., 2008, Yasuda et al., 2008, Rorsman \& Ashcroft, 2018), what exact role a KCNQ1/Kv7 channel might play in the glucose-stimulated insulin secretion process is still unclear. Notably, KCNQ1 is part of an epigenetically regulated (e.g. imprinted) genomic locus (Nakano, Murakami et al., 2006), thus, besides a potential loss of function, the mutation might be also associated with impaired expression regulation. As a strong T2D candidate (MacDonald \& Wheeler, 2003, Unoki et al., 2008, Yasuda et al., 2008), KCNQ1 might represent a potential link between various types of diabetes. The other reason is that the regulation of insulin secretion might work differently in humans and other mammalian species (Asahara, Etoh et al., 2015).

Motivated by the challenge, we sought to characterize mechanisms linking the KCNQ1 mutation to PND. Recently, the technology of generating disease-relevant human pluripotent stem cell (hPSC)-based organoid models became a vital tool in diabetes research and precision therapies (Zeng et al., 2016, Chiou et al., 2021, Zhou, Kim et al., 2018). We used CRISPR/Cas9 to introduce the KCNQ1 mutation into hESCs and then derived pancreatic endocrine organoids. The organoids proved suitable to mimic the early events in human pancreatic $\beta$-cell differentiation, but also study biological processes at later stages of maturation. The mutant cells were characterized using cellular assays and transcriptome analyses. Our data revealed that the identified (C1189T) mutation does not affect the regulation of expression or pancreatic differentiation. It is a missense mutation (R397W), resulting in a loss of channel function. Although, the mutation was previously reported from an intrauterine 
death case associated with a long QT syndrome 1 (LQT1), our study shows that the mutation causes an atypical membrane polarization of $\beta$-like cells, resulting in a variable insulin secretion phenotype. The detailed characterization of KCNQ1 function during $\beta$-cell development allowed us to decipher the role of KCNQ1 in regulating glucose metabolism in a human-specific way. This gives us a better understanding its role in pathology of NDM. 


\section{Results}

\section{Exome sequencing identifies a homozygous missense KCNQ1R397W mutation in a permanent neonatal diabetes patient}

Here, we investigate a male patient born with intrauterine growth retardation and no detectable C-peptide in his blood at birth or even later. The patient was diagnosed with permanent NDM (PND) (Fig 1A). Whole-exome sequencing of the patient and his family members revealed four candidate gene variants in KCNQ1, MIA3, NAXD (alias $C A R K D)$ and MYO1F, respectively. None of them had been previously reported in neonatal diabetes. From this list, MYO1F is not expressed at significant levels in human islets (Chiou et al., 2021). Studies had shown an association between the three other candidates and cardiovascular diseases (e.g. LQT1 (Ghosh, Nunziato et al., 2006), coronary artery disease (Samani, Erdmann et al., 2007)) or neurological disorders (Van Bergen, Guo et al., 2019, Malik, Nadir et al., 2020). Importantly, dysfunctional KCNQ1 had been reported to impair glucose stimulated insulin secretion (GSIS) in differentiated $\beta$-like cells, in both mice and humans (Zeng et al., 2016, Boini, Graf et al., 2009). KCNQ1 is also a strong candidate for type 2 (T2D) diabetes susceptibility (Unoki et al., 2008, Yasuda et al., 2008), whereas MIA3 and CARKD are weak candidates (MIA3, p value< $1 \mathrm{e}-4 ; C A R K D, \mathrm{p}$ value $=2.4 \mathrm{e}-5$ ) (Aylward, Chiou et al., 2018). Sanger sequencing confirmed the $1189 \mathrm{C}>\mathrm{T}$ nucleotide change in the exon 9 of the KCNQ1 gene, resulting in a missense mutation (R397W) (Fig 1A). The PND patient is homozygous for this mutation, while other members of his consanguineous family carry the mutation in a heterozygous form and are healthy (Fig 1A). Taken together, the mutated KCNQ1R397W was the best candidate as the cause of patient's diabetic phenotype, so we chose it for a follow-up study to decipher its potential contribution.

\section{KCNQ1R397W mutant hESCs differentiate normally into pancreatic $\beta$-like cells}

To mimic the effects of the $1189 \mathrm{C}>\mathrm{T}$ mutation in the patient, we generated an in vitro hESC-derived pancreatic islet-like organoids. First, CRISPR/Cas9 engineering was used to generate the homozygous point mutation in hESCs_H1. We established two 
KCNQ1 mutant clones from the CRISPR/Cas9 transfected cell library (KCNQ1R397W No.1 and No.2), whereas wild type (WT) and unmodified control (UC) colonies served as controls (Fig EV1A). Importantly, all of the colonies had identical hESCs morphology, stained positive for SOX2 and OCT4 (Fig EV1B), and expressed levels of OCT4, SOX2 and NANOG pluripotency markers similar to those of wild type (Fig EV1C). This indicated that the editing did not compromise pluripotency.

To determine whether the mutation affected $\beta$-cell development, we differentiated the two mutant KCNQ1 hESCs_H1 clones and their controls into pancreatic insulin+ organoids. Our protocol, based on published methods (Chiou et al., 2021, Velazco-Cruz, Song et al., 2019), was further optimized in-house (see Methods). To monitor the differentiation process, we quantified cells at each stage using flow cytometry and stage-specific markers. PDX1 (Pancreatic duodenal homeobox-1 protein) binds to the promoter of insulin and initiates insulin expression (Wang, Cahill et al., 1999, Wang, Zhou et al., 2001), and is a marker for pancreatic endoderm. As a first step, we determined the percentage of PDX1+ cells (Fig 1B). In the subsequent steps, we quantified PDX1+/NKX6.1+ (NK6 homeobox 6) cells (pancreatic endocrine precursors; Fig 1C); NKX6.1+/insulin+ cells (immature $\beta$ cells at early stages; Fig 1D); as well as NKX6.1+/insulin+ cells (matured $\beta$ cells at later stages; Fig 1E). We detected no significant differences between the clones in terms of the composition of cell types or organoid morphology (Fig EV1D), suggesting that the mutation did not significantly affect the differentiation process.

\section{The KCNQ1 R397W mutation overlaps with a CTCF binding site, but does not affect gene regulation during pancreatic differentiation}

Epigenetic modifications in the $K C N Q 1$ imprinted locus have been reported to affect $\beta$ cell mass in both human and mice (Asahara et al., 2015, Ou, Yu et al., 2019). As the KCNQ1 C1189T mutation constitutes a potentially methylated cytosine and overlaps with a predicted motif of the CCCTC-binding factor (CTCF) (Fig EV2A), we asked whether the mutation affected epigenetic gene regulation. Our data mining revealed that this particular CTCF binding site is involved in establishing chromatin loops and regulating gene expression in several human cell lines (e.g. GM12892, human lymphoblastoid and K562, human myelogenous leukemia) (Fullwood, Liu et al., 2009, 
Sabo, Hawrylycz et al., 2004, Consortium, 2012). If the mutated nucleotide is involved in epigenetic gene regulation, we would expect altered gene expression levels of $K N C Q 1$ and/or the neighboring genes, resulting in reduced $\beta$ cell numbers.

To determine whether this particular CTCF binding site is utilized during pancreatic differentiation, we analyzed active enhancer signals (H3K27ac) in ChIP-seq data, which were generated from human cells at different stages of $\beta$-cell differentiation in vitro (Xie, Everett et al., 2013). We also mined Hi-C data from human islets (Miguel-Escalada, Bonas-Guarch et al., 2019). Our analyses identified dynamic enhancer signals in intron 11 of $K C N Q 1$ but not in exon 9, in which the mutated locus resides (Fig EV2B). The analysis of the $\mathrm{Hi}-\mathrm{C}$ data further indicated that the mutated CTCF motif was not part of the pancreatic differentiation program in humans (Fig $\mathrm{EV} 2 \mathrm{C}$ ). To analyze the genomic methylation status of the mutation site of $K C N Q 1$, we performed sodium bisulfite conversion and sequencing using wild type and KCNQ1 mutant cells collected at different stages of differentiation. The assay confirmed that the C1189T mutation abolished methylation, and revealed that this cytosine was a stably methylated cytosine during pancreatic differentiation (Fig EV2D).

Analysis of RNA-seq data of pancreatic differentiation (Xie et al., 2013) revealed that the expression of $K C N Q 1$ gradually increases after the pancreatic endoderm stage to peak in islets (Fig EV2E). To examine whether the lack of methylation due to the C1189T mutation affected KCNQ1 expression, we performed both RT-qPCR and Western blotting for KCNQ1 at day 31 of differentiation. However, we observed no mutation-associated expression changes (Fig 2A and B). Furthermore, the overlapping regulatory long non-coding (Inc)RNA, KCNQ1OT1 (Asahara et al., 2015) and the other members of the imprinted locus either exhibited similar levels of expression in all the samples (e.g. CDKN1C and SLC22A18) or expressed below the threshold of detection (e.g. PHLDA2) (Fig 2C).

Next, we examined whether the C1189T mutation affected the differentiation of pancreatic endocrine cells, including $\beta$ cells. We analyzed expression levels of pancreatic hormones and quantified hormone+ cells in the pancreatic islet-like 
organoids. We found no significant differences in the expression of $\alpha$ - and $\beta$ cell-specific markers (glucagon and insulin, respectively) between mutated and control cells (Fig 2D and E). Percentages of glucagon+ and insulin+ cells were also comparable in the case and control pancreatic islet-like organoids (Fig 2F). Consistent with these findings, the proliferation rates of $\beta$-like cells were also similar in mutant and control cells (2-7\% Ki67+ cells, Fig 2G). This indicated that in line with the lack of change in the expression regulation of $K C N Q 1$, no mutation-associated changes were detected in $\beta$-cell numbers or insulin level. Collectively, methylation, ChIP-seq, Hi-C and gene expression analyses suggested that the PND phenotype, caused by the $1189 \mathrm{C}>\mathrm{T}$ mutation could not be attributed to changes in gene regulation, thus another explanation was needed.

\section{KCNQ1 ${ }^{\text {397W }} \beta$-like cells have a variable insulin secretion phenotype, depending on their maturation state}

Alternative to altering gene regulation, the mutation might compromise protein function(s). Besides production, the key function of $\beta$ cells includes insulin secretion, thus we asked whether the mutation modified this process. To this end, we subjected the organoids to both glucose (GSIS) and $\mathrm{KCl}$ depolarization (KSIS) challenges, and monitored insulin secretion at different maturation stages of the $\beta$-like cells: maturing (day 28), matured (day 31) stages. In addition, we included a late matured stage after the differentiated cells had been cultured for an extended period (day 40).

While no difference was seen in KCNQ1 transcript levels between case and control at any of the stages (Fig EV3A), We did, however, noted an altered response of KCNQ1R397W $\beta$-like cells to either GSIS or KSIS at both maturing (Fig EV3B) and matured stages (Fig 3A-D). For example, similar to the low glucose stimulation (LG) in matured $\beta$-like cells, the controls responded with $7.53 \pm 0.515$ - and $11.04 \pm 0.995$-fold induction of insulin secretion in the KSIS assay. In contrast, the response to the stimulation was significantly higher in the KCNQ1 ${ }^{\text {R397W }} \beta$-like cell lines, yielding 16.87 \pm 1.193 and $19.57 \pm 0.754$-fold enhancement (Fig $3 C$ and D). These observations suggested that the mutant cells secreted elevated levels of insulin at both maturing and matured stages. Curiously, by contrast, the late matured $\mathrm{KCNQ} 1^{\mathrm{R} 397 \mathrm{~W}} \beta$-like cells 
had a lower insulin secretion rate than controls in response to glucose stimulation, but not to $\mathrm{KCl}$ depolarization $(\mathrm{Fig} 3 \mathrm{E}-\mathrm{H})$. This is interesting, because the insulin content was not significantly different in these cells (Fig $3 \mathrm{I}$ ), indicating that the change in secretion could not be explained by the altered amount of insulin. Collectively, the mutant $\beta$-like cells exhibited a variable, stage-dependent insulin secretion phenotype, with an unusually high levels of secretion at maturing/matured- stages, and reduced levels following long-term culturing.

To monitor insulin secretion in another model, we also performed the GSIS and KSIS challenges on a mouse immortalized pancreatic $\beta$-cell line (referred to as SJ $\beta$ cells (Jia, Ivanov et al., 2015)), which had been transfected with KCNQ1R397W or WT expression constructs. Similar to our findings in the human model, SJ $\beta$ cells, which expressed the mutant $K C N Q 1$ had an altered insulin secretion rate in response to both challenges (Fig EV3C). However, we noticed two differences. First, we did not observe an increase in insulin secretion in the mouse model; it decreased upon both challenges. Second, the total insulin level was already lower in the KCNQ1R397W transfected cells compared to WT (Fig EV3D). This suggested that the reduction in insulin secretion in mouse $\beta$ cells might be explained by changes in overall insulin expression, which was not the case for the human cells. This suggests that the reduced insulin secretion, by contrast to mutant human $\beta$-like cells, might also be explained by altered insulin expression in mouse $\beta$ cells. Thus, while the mutation ultimately affected insulin secretion in both models, the mechanisms causing this might differ between species.

\section{The KCNQ1 ${ }^{\mathrm{R} 397 \mathrm{~W}}$ accelerates the rhythm of membrane depolarization/ repolarization in human $\beta$-like cells}

Our next step in investigating potential impairments in the function of KCNQ1R397W was to analyze the structure of the mutant protein. An alignment of the KCNQ1 sequence across species shows that the region immediately surrounding the mutation is highly conserved (Fig EV4A), suggesting that the mutated amino acid might be essential for proper function. In line with this, the PolyPhen2 algorithm predicted that the mutation is "probably damaging" with the high score of 0.918 (Fig EV4B). Our 
secondary structure analysis predicts that the missense mutation (R397W) of the KCNQ1 alters the structure of Helix A (Fig EV4C), one of the four predicted helical regions (Wiener, Haitin et al., 2008). As this Helix $A$ is implicated in KCNQ1's protein-protein interactions (Sun \& MacKinnon, 2017), the missense mutation of $\mathrm{R} 397 \mathrm{~W}$ might result in a loss of function of the Kv channel.

To test this hypothesis, we investigated membrane polarization. First, we performed Patch-clamp studies in cultured $\mathrm{CHO}$ cells, transfected with expression constructs, encoding KCNQ1 ${ }^{\mathrm{R} 397 \mathrm{~W}}$ or KCNQ1WT, and recorded KCNQ1 current traces. Compared to WT cells, the current density in KCNQ1R397W expressing cells was reduced (Fig 4A), consistent with effects on membrane polarization. Curiously, another patch-clamp study of HEK293 cells with the same R397W mutation, identified from a LQT1-associated fetal death case in utero, had produced similar results (Crotti, Tester et al., 2013). This raised questions about how the channel function might specifically be disrupted in $\beta$ cells, and in the context of glucose metabolism. To pursue this, we also recorded the electrical activity of human matured $\beta$-like cells that were subjected to GSIS. In addition to the high glucose challenge $(20 \mathrm{mM})$, we also used Chromanol 293B $(10 \mu \mathrm{M})$ treatment (Fig 4B), an inhibitor that blocks KCNQ1/Kv7 channel (Busch, Suessbrich et al., 1996, Bleich, Briel et al., 1997). As expected, in the UC control, both the high glucose concentration and the presence of Chromanol 293B inhibitor elevated the frequency of action potential firing (Fig 4B). In contrast, the frequency of action potential firing was higher in unstimulated KCNQ1R397W pancreatic $\beta$-like cells (e.g. at low glucose concentration and in the absence of the inhibitor) (Fig 4B). This observation suggested that the KCNQ1R397W $\beta$-like cells have a dysfunctional KCNQ1/Kv7 channel, which leads to an acceleration in the rhythm of membrane depolarization/repolarization in $\beta$-like cells.

The proteins of KCNQ1/Kv7 channel needs to traffic to the plasma membrane. As C-terminal KCNQ1 mutations had previously been reported to alter the trafficking of KCNQ1/Kv7 to the plasma membrane (Wilson, Quinn et al., 2005, Schmitt, Calloe et al., 2007), we monitored the localization of the WT and mutant proteins. Immunofluorescence microscopy revealed that both KCNQ1WT and KCNQ1R397W proteins were similarly localized at the membrane of transfected $\mathrm{CHO}$ cell (Fig EV4D), 
arguing against disrupted trafficking of the mutant form. In addition, 3D confocal scanning microscopy of the human pancreatic $\beta$-like cells similarly detected KCNQ1WT and KCNQ1 $3397 \mathrm{~W}$ proteins on the membrane in close association with cytosolic insulin (Fig EV4E).

\section{KCNQ1 ${ }^{\mathrm{R} 397 \mathrm{~W}}$ results in the accumulation of cytosolic $\mathrm{Ca}^{2+}$ in human $\beta$-like cells}

Calcium signaling is involved in synchronizing the periodic change of glucose concentration in $\beta$ cells (Pagliuca, Millman et al., 2014). To find out whether the elevated channel activities affected $\mathrm{Ca}^{2+}$ levels in the mutated $\beta$-like cells, we monitored the dynamics of cytoplasmic $\mathrm{Ca}^{2+}$ concentrations. In the Fluo-4AM-labelled $\mathrm{Ca}^{2+}$ flux analysis, we challenged the mutant and control organoids in their matured stage with either high glucose stimulation (GSIS) or chromanol 293B inhibitor treatment. The analyses revealed increases in the cytoplasmic $\mathrm{Ca}^{2+}$ concentrations in both control and mutant $\beta$-like cells in response to the high glucose stimulation (Fig 4C). However, the mutant cells had a relatively more robust response to the elevated glucose stimulation, and did not return to the baseline in their "resting" stage (Fig 4C). Similar, under chromanol 293B treatment, the mutant cells displayed higher elevation of cytoplasmic $\mathrm{Ca}^{2+}$ concentrations, and did not completely recover their original levels following the challenge, compared to cells that were not treated with inhibitors e.g. WT, UC and human islets) (Fig 4D and EV4F). The observation that the mutant cells had a more robust response to stimulation and failed to properly return to their baseline suggested that these cells might eventually accumulate an abnormally elevated cytosolic $\mathrm{Ca}^{2+}$ level upon challenges with glucose.

\section{KCNQ1 R397W $\beta$-like cells accumulate crystallized insulin granules}

How would elevated levels of cytosolic $\mathrm{Ca}^{2+}$ affect $\beta$ cells? In $\beta$ cells, $\mathrm{Ca}^{2+}$ contributes to the formation of secretory granules that structurally organize insulin in $\left(\mathrm{Zn}^{2+}\right)_{2}\left(\mathrm{Ca}^{2+}\right)$ Insulin 6 crystals (Rorsman \& Ashcroft, 2018, Dunn, 2005). We used electron microscopy to determine whether the insulin granules differed between mutant $\beta$-like cells and their controls. We observed that the structure of insulin granules was consistent with their matured stage, and was similar to those reported 
from human islets (Deconinck, Potvliege et al., 1971). However, $\beta$-like cells derived from the mutant clones had a significantly higher number of crystallized insulin granules than the controls (e.g. wild type and unmodified control) (Fig 4E). These data suggested that the elevated cytoplasmic $\mathrm{Ca}^{2+}$ level resulted in a more extensive crystallization of insulin, leading to an accumulation of secretory granules. As a downstream effect, this might be linked to the observed elevation in the rate of insulin secretion.

\section{Reduced glucose transporter 1 (GLUT1) expression in late matured KCNQ1R397W $\beta$-like cells}

Could the dysfunctional KCNQ1/Kv7 channel disturb global gene expression and affect biological processes in human $\beta$-like cells? To answer, we performed RNA-sequencing on mutant and control samples (at day 32, matured stage) and compared their transcriptomes. The analysis considered only differently expressed genes (DEGs) that were found in both mutated colonies and were also differently expressed from both controls (e.g. WT and UC) (Fig EV5A). The gene ontology (GO) categories that were most significantly affected included oxidative phosphorylation, MAPK signaling pathways and MODY(Fig 5A).

RNA-seq identified a set of upregulated genes (e.g. UOCHR, NDUFS5, COX7a, COX411, NDUFB2, NDUFB5, ATP5F1C) in the oxidative phosphorylation pathway (Fig 5A). The upregulation of this metabolic process is expected to increase ATP synthesis in the mitochondria (Siengdee, Trakooljul et al., 2015, Hwang, Lynn et al., 2015, Ikeda, Shiba et al., 2013), which is required for the KATP channel-dependent secretion of insulin by $\beta$ cells (Haythorne, Rohm et al., 2019, Fu, Gilbert et al., 2013). Electron microscopy revealed comparable numbers of mitochondria in both controls and mutant colonies (Fig 4E), suggesting that the altered oxidative phosphorylation properties of the mutant cells did not affect the mass of these organelles. In the mutant cells, we also observed the transcriptional downregulation of genes upstream of the classical MAPK signaling pathway (Fig 5A), including those encoding calcium channel subunits (CACNs) (e.g. CACNA1A, CACNA1C) and receptor tyrosine kinases (RTKs) RTKs include the members of the fibroblast growth factor receptor 
(FGFR) family (e.g. FGFRL1, FGFR1, FGFR3 and FGFR4) that play roles in regulating metabolic features of $\beta$ cells (Rorsman \& Ashcroft, 2018, Wente, Efanov et al., 2006, Miralles, Czernichow et al., 1999, Hart, Baeza et al., 2000). In addition, our RNA-seq analysis identified two down-regulated DEGs: HNF4a (hepatocyte nuclear factor $4 \alpha$ ) and NEUROD1 (Neuronal Differentiation 1) of the MODY gene set of hereditary monogenic diabetes (Fig 5A). HNF4a is a transcription factor expressed in liver, kidney and pancreas (Sladek, Zhong et al., 1990, Miquerol, Lopez et al., 1994), and is thought to be a downstream target of FGFRs (Twaroski, Mallanna et al., 2015).

The identification of metabolic genes among the DEGs in the transcriptome of KCNQ1R397W $\beta$-like cells suggested a potential link between the metabolic features and the changes in the insulin secretion phenotype (Fig 3). To investigate this further, we generated an expanded list of candidate genes including FGFRs and some of their downstream targets, and performed qPCR on samples collected at the different stages. In the late matured KCNQ1R397W $\beta$-like cells, qPCR revealed lower levels of FGFRL 1, FGFR1 and HNF4a than both controls (Fig EV5B). These results suggested a negative effect on metabolic regulation of mutant $\beta$-like cells that had been subjected to extended culturing. In a similar assay, we also tested PDX1, which is regulated by FGFR1 and HNF4a (Hart et al., 2000, Narla, Lee et al., 2017, Kuo, Conley et al., 1992, Gerrish, Cissell et al., 2001) (Fig EV5B). We also assayed GLUT2, the major glucose transporter in mice, whose expression level is controlled by Fgfr1 or Pdx1 in mouse $\beta$-cells (Hart et al., 2000, Waeber, Thompson et al., 1996, Ahlgren, Jonsson et al., 1998, Brissova, Shiota et al., 2002), and which has been previously linked to transient neonatal diabetes (Sansbury, Flanagan et al., 2012). Finally, we added GLUT1 to the list, which has been proposed as the predominant glucose transporter in human $\beta$ cells (De Vos, Heimberg et al., 1995). Our qPCR analysis revealed a significant expressional decrease of PDX1 and GLUT1 in late matured KCNQ1R397W $\beta$-like cells, a finding that we also confirmed by immunohistochemical staining (Fig EV5B, EV5C and 5C). However, unlike in mouse $\beta$ cells, the downregulated FGFR1 or PDX1 did not affect the transcription level of GLUT2 (Fig 5B). This observation can be explained by the fact that each species relies mainly on a different glucose transporters (De Vos et al., 1995). To follow up on the data of GLUT1-downregulation in late matured stage, we performed additional 
immunohistochemical staining of GLUT1+ cells, both with and without chromanol 293B inhibitor treatment (Fig 5D). The treatment decreased the number of control GLUT1+ cells to a similar level of the comparator of mutant cells, which had not been treated with the inhibitor (Fig 5D), arguing for a correlation between KCNQ1/Kv7 dysfunction and the expression of GLUT1.

\section{Chronic exposure to high glucose results in the loss of KCNQ1R397W $\beta$-like cells}

Because hyperglycemia accelerates $\beta$ cell dysfunction in type 2 diabetes (Robertson, Harmon et al., 2003), we asked whether the KCNQ1R397W $\beta$-like cells exhibited the similar phenotype of glucose-induced toxicity. To this end, we incubated matured KCNQ1 R397W and control $\beta$-like cells for seven days in regular S7 media (control) and in parallel, in S7 media supplemented with high concentration of glucose (20 mM). In high glucose conditions, both flow cytometry and immunostaining revealed a significant decrease in the number of insulin+ KCNQ1 R397W $\beta$-like cells compared to controls (Fig 6A and EV5D). In regular S7 media, there was a much smaller decreasing trend (Fig 6A and EV5D). This suggests that under chronic exposure to high glucose, the number of insulin+ mutant cells fell at an accelerated rate.

Long-term elevation of cytoplasmic $\mathrm{Ca}^{2+}$ or overstimulation of the $\mathrm{Ca}^{2+}$ signaling pathway have been shown to decrease $\beta$-cell mass and function via induced cell death (Bernal-Mizrachi, Cras-Meneur et al., 2010, Kato, Oya et al., 2008, Epstein, Overbeek et al., 1989). To find out whether the accumulated cytoplasmic $\mathrm{Ca}^{2+}$ might induce apoptosis at the late matured stage of KCNQ1-mutant $\beta$-like cells, we quantified cells labeled with pro-apoptotic markers (Annexin V+/7-AAD-) (Fig 6B). FACS quantification revealed a significantly higher number of cells stained for the pro-apoptotic markers in KCNQ1 ${ }^{\mathrm{R} 397 \mathrm{~W}} \beta$-like cells at their late matured stage, when compared to controls (Fig 6B). This observation pinpoints that induced cell death may contribute to the reduced insulin secretion of KCNQ1 ${ }^{\mathrm{R} 397 \mathrm{~W}} \beta$-like cells at their late matured stage. 


\section{Discussion}

Here, we report the case of a patient, diagnosed with permanent neonatal diabetes (PND). The patient exhibited no detectable endogenous insulin secretion after birth, and carried a homozygous missense C1189T mutation (R397W) of KCNQ1. We replicated the defect in a pancreatic organoid model, using CRISPR/Cas9 editing of human embryonic stem cells (hESCs). Using our model, we show that the mutation results in a compromised function of KCNQ1/Kv7 channel, and contributes to a differentiation stage-dependent, variable insulin secretion phenotype. This model also helped us to decipher how the blocked KCNQ1/Kv7 channel could eventually lead to a hypo-insulinemic phenotype of the patient.

In addition to the KCNQ1 gene, the KCNQ1 locus encodes the IncRNA (KCNQ1OT1), which controls multiple genes in the imprinted genomic locus (Zhang, Zeitz et al., 2014). This epigenetically sensitive genomic region provides a binding platform for several transcription factors including CTCF, which has been implicated in chromatin looping (Ong \& Corces, 2014). The C1189T mutation abolishes the methylation of a cytosine and overlaps with a CTCF binding site that is occupied in several tissues (Fullwood et al., 2009, Sabo et al., 2004, Consortium, 2012). 3D chromatin analyses predict that this genomic region can adopt several alternative chromatin-loops that potentially affect gene regulation and are likely regulated on development/tissue specific manner (Sams, Nardone et al., 2016, Tang, Chen et al., 2011, Soshnikova, Montavon et al., 2010, Welsh, Kwak et al., 2015). However, the CTCF affected by the mutation is not used in pancreatic differentiation, and the mutation does not affect the regulation of $K C N Q 1$ expression on an epigenetic level. Correspondingly, the C1189T mutation does not alter the differentiation and proliferation properties of the cells, and the mutant phenotype is detectable only in the differentiated $\beta$-cells.

Our study clearly demonstrates that the mutation compromises the KCNQ1/Kv7 channel function. The mutated amino acid (R397W) of the KCNQ1 protein disrupts the secondary structure of Helix A. The C-terminal structures of Helix A and Helix B form a clamshell-like structure that is essential for calmodulin (CaM) binding, and this regulates the formation of the functional KCNQ1/Kv7 channel (Sun \& MacKinnon, 
2017). As a result, the mutation disrupts the generation of delayed outward $\mathrm{K}^{+}$current (outward rectification) (Rorsman \& Ashcroft, 2018), which in turn is predicted to reduce voltage-gated activation. This was confirmed in our Patch-clamp studies and in vitro electrophysiological analyses. The dysfunctional KCNQ1/Kv7 channel exhibits altered ATP sensitivity ( $\mathrm{Li}$, Gao et al., 2013), and this contributes to downstream processes. One way is by upregulating oxidative phosphorylation, which could modulate the activities of additional channels (e.g. KATP channels and Cav) in KCNQ1R397W $\beta$-like cells. The altered $\mathrm{Ca}^{2+}$ influx leads to elevated levels of cytoplasmic $\mathrm{Ca}^{2+}$. As $\mathrm{Ca}^{2+}$ and insulin generate hexameric structures (Rorsman \& Ashcroft, 2018, Dunn, 2005), this process promotes the crystallization of insulin into secretory insulin granules. Accumulated cytoplasmic $\mathrm{Ca}^{2+}$ thus triggers a cascade of insulin secretion through granule exocytosis in $\beta$ cells (Fridlyand, Jacobson et al., 2013).

Over the long run, however, the above process decreases cellular metabolism, and ultimately causes cells to reduce their secretion of insulin. We also noted that a chronic exposure of KCNQ1R397W $\beta$-like cells to high glucose promotes an irreversible deterioration of the cells in a way characteristic for diabetic conditions (Robertson et al., 2003). Overstimulation of cytosolic $\mathrm{Ca}^{2+}$ likely activates an additional downstream process, the NLPR3 inflammasome pathway (Murakami, Ockinger et al., 2012, Rossol, Pierer et al., 2012), that was reported to induce apoptosis in vivo (Bernal-Mizrachi et al., 2010, Kato et al., 2008, Epstein et al., 1989). Our comprehensive analysis of the KCNQ1R397W organoid let us hypothesize that by birth, the impaired function of $\beta$-cells and the loss of $\beta$ cell mass might have decreased the secretion of insulin into the patient's blood to levels that were below detection. Thus, the homozygous C1189T mutation, identified in the patient might explain the phenotype of permanent neonatal diabetes (PND). 
Several mutations of $K C N Q 1$, which affect the C-terminal A and B Helices of KCNQ1, have been linked to irregular heartbeat (LQT1) (Ghosh et al., 2006), and the function of KCNQ1 as a voltage-gated potassium channel is well characterized for the repolarization phase of the cardiac action potential (Bellocq et al., 2004). In contrast, the exact role of KCNQ1 in glucose metabolism is still enigmatic. In a genetic survey for LQT1 syndrome, the $1189 \mathrm{C}>\mathrm{T}$ nucleotide change was classified as a mutation whose pathological significance was unknown (Kapplinger, Tester et al., 2009). However, the same mutation was reported as a loss of function and the potential cause of an intrauterine fetal death case (16-weak-old female), supported by a significant reduction (>70\%) in $\mathrm{I}_{\mathrm{Ks}}$ density in HEK273 cells using Patch-clamp (Crotti et al., 2013). This reduction is consistent with the in vitro electrophysiological phenotype of a mutation that causes LQT1 and impairments of channel functions in cardiomyocytes (Bellocq, van Ginneken et al., 2004). Here, our organoid model demonstrates clearly that this mutation of $K C N Q 1$ affects the rhythm of membrane depolarization/repolarization of $\beta$-cells and, as a result, their secretion of insulin. Furthermore, our patient's condition of is stable under regular insulin treatment, and shows no sign of the cardiovascular phenotype. This suggests that the disease is caused by defects in the production of insulin and/or its secretion by $\beta$ cells.

In fact, there is no clear connection between the cardiovascular and metabolic phenotypes associated with KCNQ1. The LQT1-syndrome has incomplete clinical penetrance in single families that carry heterozygous $K C N Q 1$ mutations. One explanation for the lack of clarity might be that the cardiovascular and metabolic syndromes appear at different stages of a patient's life. In line with this, a study that monitored fourteen LQT1 patients with dominant-negative mutations of KCNQ1 found that all developed postprandial hyper-insulinemia, but only at ages over 40 (Torekov, lepsen et al., 2014). Our patient is younger than the onset of LQT1 syndrome (transitional period is 12 to 14 years old; fatal period is the median age of 32 (Guettler, Rajappan et al., 2019), which mean that it might simply be too early to draw any conclusions about the cardiovascular aspects of his disease.

Deciphering the exact role of KCNQ1/Kv7 channel in glucose metabolism was also hampered by the occasional contradictory reports on hypo- and hyper-insulinemic 
phenotypes. For example, it has been reported that knocking out KCNQ1 led to impaired GSIS in differentiated $\beta$-like cells in both mice and humans (Zeng et al., 2016, Boini et al., 2009). In contrast, blocking the KCNQ1/Kv7 channel and the following increase of cytoplasmic $\mathrm{Ca}^{2+}$ concentration results in hyper-insulinemia in rats (Finol-Urdaneta, Remedi et al., 2012). Furthermore, the forced expression of $K C N Q 1$ has been also associated with dysfunctional insulin exocytosis (Yamagata, Senokuchi et al., 2011). Importantly, our organoids could model both the hypo- and hyper-insulinemic phenotypes of the compromised KCNQ1. We could link these two phenotypes to the different maturation stages of $\beta$ cells.

Species-specific differences in glucose metabolism may have contributed to the complexity of deciphering KCNQ1/Kv7's roles in glucose metabolism; they may also explain some of the contradictions. Our animal disease model revealed that the impaired secretion of insulin exhibits only the hypo- (but not the hyper-) insulinemic phenotype in mouse $\beta$ cells, in contrast to situation in humans. The decrease in insulin secretion may be due to a reduction in levels of expression of insulin, which is not observed in human $\beta$ cells, suggesting a species-specific difference in the regulation of insulin production. We also detected a difference in the regulation of GLUT1/GLUT2 in human and mice $\beta$ cells, which supports previous observations that GLUT1 is the primary glucose transporter in human pancreatic cells (De Vos et al., 1995). In mice $\beta$ cells, both Fgfrl1 and $P d x 1$ have been shown to regulate the expression of Glut2 (Hart et al., 2000, Waeber et al., 1996, Ahlgren et al., 1998, Brissova et al., 2002. In human $\beta$-like cells, by contrast, KCNQ1R397W did not affect GLUT2. Instead, reductions of FGFR1 and PDX1, downregulated GLUT1 and directly impaired GSIS.

Finally, our study highlights that the pathogenic phenotype is a contingent one. While the same R397W mutation was reported from an intrauterine death case (Crotti et al., 2013), our patient survived, and so far, his heterozygotic family members are asymptomatic. We observed a downregulation of $H N F 4 \alpha$, a MODY factor (Sanyoura et al., 2018), which might play a role in both the appearance and severity of the diseased phenotype. Potentially our study might help to decipher a potential link between mono- and polygenetic forms of diabetes (KCNQ1-PND, HNF4a-MODY and 
T2D). Additional factors, in conjunction with the homozygous KCNQ1R397W mutation might accelerate the mass deterioration of $\beta$-cells, through (epi)genetic or environmental mechanisms that remain to be identified. 


\section{Experimental Procedures}

\section{Patients and genetic discovering}

The patients were recruited from Charité. We excluded mutations in known genes causing neonatal diabetes $(A B C C 8, K C N J 11, I N S)$ or hyperinsulinemic hypoglycemia (GCK, HNF4A, GLUD1, ABCC8, KCNJ11) by Sanger sequencing. We performed exome sequencing in the child with neonatal diabetes and his consanguineous parents using the Agilent SureSelect Human All Exon Kit (Agilent SureSelect v4, $50 \mathrm{Mb})$. We analyzed the data with our established pipeline in the institute (Kuhnen, Turan et al., 2014) and confirmed the KCNQ1 mutations by Sanger sequencing (Table S1) of the families. The Charite committee on human research approved the study (EA-No EA2/054/11) and written informed consent was obtained.

\section{Electrophysiology analysis of KCNQ1-R397W in CHO cells}

Chinese hamster ovary ( $\mathrm{CHO}$ ) cells were cultured in Hams F12 medium supplemented with $10 \%$ FBS and 1\% Strep/Pen in incubator. Cells were treated with trypsin-EDTA and plated on glass coverslips (Menzel, precoated with gelatin for $1 \mathrm{~h}$ ) in 6 well plates. We performed mutagenesis with the primers (Table S1) designed for the R397W mutation according to the manufacturer's instruction (QuikChange II Site-Directed Mutagenesis Kit, Agilent Technologies, USA). Upon reaching 50-60\% density, cells were transiently transfected with $2 \mu \mathrm{g}$ human $K C N Q 1 \mathrm{cDNA}$ or $2 \mu \mathrm{g}$ of human KCNQ1-R397W cDNA (pIRES-AcGFP1 vector, 19 cells) respectively, using SuperFect Transfection Reagent (Qiagen) according to the manufacture's protocol. GFP protein expression was used to visually identify transfected $\mathrm{CHO}$ cells expressing KCNQ1 or KCNQ1-R397W. Patch-clamp recordings were obtained 48-72h after transfection.

Patch-clamp recorded (voltage-clamp whole-cell mode) at RT. The coverslips containing adherent transiently transfected $\mathrm{CHO}$ cells were transferred to a glass dish containing extracellular bath solution (135 mM NaCl, $5 \mathrm{mM} \mathrm{KCl}, 1.3 \mathrm{mM} \mathrm{MgCl} 2,5 \mathrm{mM}$ HEPES, $2.5 \mathrm{mM} \mathrm{CaCl}$, $10 \mathrm{mM}$ d-glucose, adjusted to $\mathrm{pH} 7.4$ using $\mathrm{NaOH}$ ). Pipettes were pulled from a vertical puller (Narishige, Tokyo) and maintained a resistance of 
3-6 $\mathrm{M} \Omega$ when filled with the intracellular solution $(10 \mathrm{mM} \mathrm{NaCl}, 120 \mathrm{mM} \mathrm{KCl}, 2 \mathrm{mM}$ $\mathrm{MgCl} 2,11 \mathrm{mM}$ HEPES, $1 \mathrm{mM} \mathrm{CaCl}$, $11 \mathrm{mM}$ EGTA, adjusted to $\mathrm{pH} 7.2$ using $\mathrm{KOH}$ ). The glass dish was placed under an inverted microscope equipped with fluorescence optics for green fluorescent protein detection (Olympus IX71 inverted microscope) to identify KCNQ1 and KCNQ1-R397W transfected CHO cells. Electrophysiological data were acquired via a Multiclamp 700B amplifier and a Digidata 1440A acquisition system. Test currents were elicited from a holding voltage of $-100 \mathrm{mV}$ by potentials ranging from $-100 \mathrm{mV}$ to $+80 \mathrm{mV}$ in $20 \mathrm{mV}$ increments for KCNQ1 and the corresponding mutant KCNQ1-R397W. Leak subtraction was not applied. The individual cell current amplitudes were normalized to cell size (whole-cell membrane capacitance). Data were analyzed using pClamp 10.3 software (Molecular Devices) and statistical analysis (t-test, Mean \pm SEM).

\section{Generation of KCNQ1 ${ }^{\mathrm{R} 397 \mathrm{~W}}$ mutant hESC cell lines}

For an easy identification of the engineered cells, we used a CRISPR-Cas9 dependent homology-directed genome editing system that co-expresses a fluorescent marker (Richardson, Ray et al., 2016). The gRNA targeting the mutation of KCNQ1 was designed and inserted into Px458-GFP cloning backbones (Addgene) for co-expression with Cas9. Single-stranded DNA (ssDNA) donors were designed as per Christopher' protocol (Richardson et al., 2016). gRNA and SsDNA sequences used are listed in Table S2. The plasmids and ssDNA were transfected into hESC_H1 (WiCell) of $70-85 \%$ confluency using the XtremeGENE 9 transfection reagent (Roche). After 48 hours, the cells were dissociated to single-cell suspension using Accutase (StemPro) and sort GFP positive cells. To generate stable hESCs colonies from the fluorescent cell library, single colonies were picked and transferred to and cultured on Matrigel (Corning)-coated 48-well plates. To verify their genotype, we collected dead cells/debris floating in the culture media and PCR-amplified the CRISPR-edited genomic region. Amplicons were subjected to Sanger sequencing. Primers are listed in Table S3. Positive colonies and some unmodified colonies were continually cultured. Cell colonies were separately dissociated and transferred into 6-well plates using ReLeSR (Stem Cell Technologies). Differentiated cells were removed by using a pipette tip to minimize spontaneous differentiation. The high pluripotent stem cells form colonies were selected by Anti-Tra-1-60-PE and Anti-PE 
MicroBeads following the manufacturer's instructions (MACS Miltenyi Biotec). The stable colonies were frozen down at $-80^{\circ} \mathrm{C}$. To eliminate the potential off-target events generated by the CRISPR system, we established one unmodified control (UC) and generated two KCNQ1 mutant clones (KCNQ1R397W No.1 and No.2) from the CRISPR/Cas9 transfected cell library. Robert Koch institute approved the associated studies in hESC_H1 (AZ: 3.04.02/0147).

\section{Generation of human pancreatic $\beta$-like cells}

hESCs were developed toward insulin+ cells in a suspension-based format on a shaker with minor modification to the published protocol (Chiou et al., 2021, Velazco-Cruz et al., 2019). The single cells were seeded in mTeSR1 media (Stem Cell Technologies) supplemented with CloneR (Stem Cell Technologies) in 6-well ultra-low attachment plates at $5.5 \times 10^{6}$ cells/well. The plates were cultured on the shaker (Binder) at $100 \mathrm{rpm}$ in a $\mathrm{CO}_{2}$ incubator (Binder) for $24 \mathrm{~h}$. Undifferentiated aggregates were cultured in daily differentiation media.

S1/S2 basal media: $500 \mathrm{~mL}$ MCDB131 (Life Technologies) supplemented with $0.75 \mathrm{~g}$ $\mathrm{NaHCO}_{3}, 1 \%$ GlutaMAX (Life Technologies), $15 \mathrm{mM}$ glucose (Sigma) and $2.5 \mathrm{~g}$ fatty acid-free BSA (Proliant Biologicals).

S3/S4 basal media: $500 \mathrm{~mL}$ MCDB131 supplemented with $1.25 \mathrm{~g} \mathrm{NaHCO}_{3}, 1 \%$ GlutaMAX, $15 \mathrm{mM}$ glucose and $10 \mathrm{~g}$ fatty acid-free BSA.

S5/S6 basal media: $500 \mathrm{~mL}$ MCDB131 supplemented with $0.75 \mathrm{~g} \mathrm{NaHCO}_{3}, 1 \%$ GlutaMAX, $20 \mathrm{mM}$ glucose and $10 \mathrm{~g}$ fatty acid-free BSA.

Day 0 media: S1/S2 basal media, $100 \mathrm{ng} / \mathrm{mL}$ Activin A (R\&D Systems), $25 \mathrm{ng} / \mathrm{mL}$ mouse Wnt3a (R\&D Systems).

Day 1 - Day 2 media: S1/S2 basal media, $100 \mathrm{ng} / \mathrm{mL}$ Activin A.

Day 3 - Day 5 media: S1/S2 basal media, 50 ng/mL KGF (R\&D Systems), 0.25 mM ascorbic acid (Sigma).

Day 6 - Day 7 media: S3/S4 basal media, 50ng/mL KGF, 0.25 M SANT-1 (Sigma), 1 MM RA (Sigma), 100 nM LDN-193189 (Stemgent), 200 nM TPB (EMD Millipore), 0.25 $\mathrm{mM}$ ascorbic acid, 0.5\% ITS-X (ThermoFisher).

The plates were cultured on the shaker at $120 \mathrm{rpm}$ in $\mathrm{CO}_{2}$ incubator from day 8 to day 20. 
Day 8 - Day 10 media: S3/S4 basal media, 2ng/mL KGF, $0.25 \mu \mathrm{M}$ SANT-1, $0.1 \mu \mathrm{M}$ RA, 200 nM LDN-193189, 100 nM TPB, 0.25 mM ascorbic acid, 0.5\% ITS-X.

Day 11 - Day 13 media: S5/S6 basal media, $0.25 \mu \mathrm{M}$ SANT-1, $0.05 \mu \mathrm{M}$ RA, $100 \mathrm{nM}$

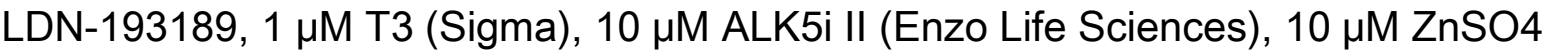
(Sigma), $10 \mu \mathrm{g} / \mathrm{mL}$ heparin (Sigma), $0.25 \mathrm{mM}$ ascorbic acid, 0.5\% ITS-X.

Day 14 - Day 20 media: S5/S6 basal media, 100 nM LDN-193189, 1 M T3, $10 \mu \mathrm{M}$ ALK5i II, $10 \mu \mathrm{M}$ ZnSO4, $10 \mu \mathrm{g} / \mathrm{mL}$ heparin, 100nM $\gamma$-secretase inhibitor XX (Calbiochem), 0.5\% ITS-X.

S7 media (day 21-day 40): $500 \mathrm{~mL}$ MCDB131 supplemented with 1\% GlutaMAX, $10 \mathrm{~g}$ fatty acid-free BSA, 5mg heparin, 5mL MEM nonessential amino acids, 84 mg ZnSO4, $500 \mu \mathrm{L}$ Trace Elements A and $500 \mu \mathrm{L}$ Trace Elements B. Day 21 aggregates were dissociated to single cells and were seeded in S7 media supplemented with CloneR in 6-well ultra-low attachment plates at $5.5 \times 10^{6}$ cells/well. The plates were cultured on the shaker at $100 \mathrm{rpm}$ in a $\mathrm{CO}_{2}$ incubator for $24 \mathrm{~h}$. Day22 aggregates were cultured in standard S7 media without CloneR at 120 rpm.

\section{Flow cytometry analysis}

The cell aggregates were treated with TrypLE (10X, ThermoFisher) to dissociate to single cells. The single cells were re-suspended with cold BD fixation/permeabilization solution following the manufacturer's instructions (BD Biosciences). Quality control of the differentiation was performed by flow cytometry analysis of stage specific markers (Table S4). Corresponding isotypes antibodies were loaded into another suspension aliquot as isotope control. Cells were washed and suspended into $0.2 \%$ BSA after aspirating supernatant. The samples were analyzed on a flow cytometer after the compensation setting.

\section{Immunofluorescence analysis}

Organoids were fixed in 4\% PFA and dehydrated in 30\% sucrose (w/v). Organoids were transferred to the center of flat bottom cryosectioning molds (VWR). The mold was filled with OCT and placed in a dry ice ethanol bath to freeze OCT (VWR). Organoids were embedded in frozen OCT and stored at $-80^{\circ} \mathrm{C}$. The embedded 
organoids were sectioned by using CRYOSTAT MICROTOM (Thermo Scientific). Sectioned slides were washed by DPBS to get rid of OCT. The slide was incubated with respective primary antibody and second antibody solutions after blocking. The nuclei were stained with DAPI (fisher scientific). The slides were mounted with VECTASHIELD® Antifade Mounting Medium (Vector Laboratories) and covered with coverslips. The mounted and covered slide was sealed with CoverGripTM Coverslip Sealant (Biotium) and allowed to dry fully before analyzed on LSM700 inverted fluorescent microscope (Zeiss). Depending on the antibody combinations, the 405, 488, 555 and $640 \mathrm{~nm}$ excitation lasers were used in sequential scans to prevent cross-talk between the detection fluorescence channels. The slides were stored long-term at $-80^{\circ} \mathrm{C}$. Antibodies used are listed in Table S4.

\section{Gene expression analysis (qRT-PCR)}

Total RNA was extracted from cells using the Direct-zol RNA MiniPrep Plus kit following the manufacturer's instructions (Zymo research) and used for cDNA reverse transcription (Applied Biosystems). Gene expression was assessed on the $7900 \mathrm{HT}$ Fast Real-Time PCR System (Applied Biosystems) using the Power SYBR Green PCR Master Mix (Applied Biosystems). Data were normalized to GAPDH or TBP expression using the $\Delta \Delta \mathrm{Ct}$ method. Primers used are listed in Table S3.

\section{$K C N Q 1$ mutation locus methylation analysis}

The cell aggregates were lysed in lysis buffer $(100 \mathrm{mM}$ Tirs-HCl, $0.5 \mathrm{M}$ EDTA, $10 \%$ SDS, $5 \mathrm{M} \mathrm{NaCl}, 0.05 \%$ Protein $\mathrm{K}$ ) and incubated at $55^{\circ} \mathrm{C}$ overnight. The lysate was mixed with an equal volume of phenol: chloroform: isoamyl alcohol solution (Roch). The aqueous phase (upper) was mixed with a $10 \%$ volume of $3 \mathrm{M}$ sodium acetate $(\mathrm{pH} 5.2)$ and a 2 -fold volume of $-20^{\circ} \mathrm{C}$ cold $100 \%$ ethanol. The mixture was placed at $-80^{\circ} \mathrm{C}$ overnight. The supernatant was carefully removed after DNA was settled down by gravity. The DNA pellet was washed with $70 \%$ ethanol. The DNA pellet was allowed to air dry for 15 min before resuspending in Nuclear free $\mathrm{H}_{2} \mathrm{O}$ (Sigma). Sodium bisulfite conversion of unmethylated cytosines in DNA was based on EpiTect Bisulfite Handbook (Qiagen). We designed primers (Table S3) from MethPrimer to sequence the KCNQ1 mutation locus. 


\section{Western blotting}

Organoids were lysed in RIPA buffer (50 mM Tris- $\mathrm{HCl}$ pH7.4, $150 \mathrm{mM} \mathrm{NaCl}, 1 \mathrm{mM}$ EDTA, 1\% Triton-100, 1\% Na-Deoxycholate and $0.1 \%$ SDS). The procedure of protein concentration determination was based on the manual of the Pierce BCA Protein Assay Kit (Pierce). Protein samples were boiled at $95^{\circ} \mathrm{C}$ for $5 \mathrm{~min}$ and were run on a TGX Stain-Free acrylamide gel. The gel was prepared by following the manual of the TGX Stain-Free FastCast Acrylamide Kit (BioRad). The proteins were transferred onto a PVDF membrane (BioRad) following the guide of the Trans-Blot Turbo transfer system RTA Transfer Kit (BioRad). The PVDF membrane was blocked and then incubated with KCNQ1 antibodies (ATLAS ANTIBODIES) overnight at $4^{\circ} \mathrm{C}$. The PVDF membrane was washed with TBST buffer and incubated with HPR-Anti rabbit lgG (Thermo Scientific) for $1 \mathrm{~h}$ at room temperature. For detection of KCNQ1, the PVDF membrane was developed with SuperSignal West Femto Maximum Sensitivity Substrate (Thermo Scientific). The antibodies were removed by the mild stripping buffer (15 g Glycine, $1 \mathrm{~g}$ SDS, $10 \mathrm{~mL}$ Tween 20, add $\mathrm{dd}_{2} \mathrm{O}$ to $1 \mathrm{~L}, \mathrm{pH}$ 2.2). The PVDF membrane was blocked and incubated with Actin antibodies (Dianova) overnight at $4^{\circ} \mathrm{C}$. The PVDF membrane was incubated with HPR-Anti mouse IgG (Thermo Scientific) for $1 \mathrm{~h}$ at room temperature. For detection of Actin, the membrane was developed with ECL reagents (Cytiva). The PVDF membrane was imaged on the ChemiDocTM MP imaging system (BioRad).

\section{Insulin secretion analysis of human KCNQ1R397W $\beta$-like cells}

The organoids were transferred to 6 -well ultra-low attachment plates with $5 \mathrm{~mL}$ KRB buffer (130 mM NaCl, 5 mM KCl, 1.2 mM CaCl2, 1.2 mM MgCl2,1.2 mM KH2PO4, 20 $\mathrm{mM}$ Hepes (pH 7.4), $25 \mathrm{mM} \mathrm{NaHCO3,0.1 \%} \mathrm{BSA)} \mathrm{containing} 2.75 \mathrm{mM}$ glucose. The plates were incubated for $1 \mathrm{~h}$ in a $37^{\circ} \mathrm{C}$ incubator. 5 organoids/well were transferred to 96-well plates with 10 replicates.

Insulin secretion stimulated by glucose or $\mathrm{KCl}$ was firstly measured by adding 2.75 $\mathrm{mM}$ glucose KRB buffer until $200 \mu \mathrm{L} /$ well. The organoids were incubated $30 \mathrm{~min}$ in a $37^{\circ} \mathrm{C}$ incubator. $190 \mu \mathrm{L}$ solution per well was transferred into a new 96-well plate, 
respectively. Fresh $190 \mu \mathrm{L} 16.8 \mathrm{mM}$ glucose KRB buffer solution or $30 \mathrm{mM} \mathrm{KCl} \mathrm{KRB}$ buffer per well was added back to the previous well following by incubation for 30 min in a $37^{\circ} \mathrm{C}$ incubator. $190 \mu \mathrm{L}$ solution per well was transferred into a new well of 96 -well plate, respectively. Total insulin was measured by adding the acid ethanol solution $\left(1.5 \% \mathrm{HCl}, 80 \%\right.$ ethanol) until $200 \mu \mathrm{L} /$ well. The organoids were incubated at $4^{\circ} \mathrm{C}$ overnight on the shaker at $100 \mathrm{rpm} .190 \mu \mathrm{L}$ solution per well was transferred into a new well of 96 -well plate, respectively. The new 96 -well plates were frozen at $-80^{\circ} \mathrm{C}$ for ELISA measurement.

The released and total insulin was measure by the Human insulin ELISA Kit following the manufacturer's instructions (ALPCO). The organoids were collected into 50 $\mu \mathrm{L} /$ well sonication buffer (10 mM Tirs, $1 \mathrm{mM}$ EDTA, 0.2\% Triton-X 100, 0.05\% Protein K). The organoids were sonicated 5 cycles ( $30 \mathrm{~s}$ ON and $30 \mathrm{~s}$ OFF) in Bioruptor Pico Sonication device (diagenode). The DNA of organoids was detected by using dsDNA Broad Range Assay (DeNovix). The DNA concentration was calculated by using DeNovix DS-11 FX Fluorometer (DeNovix). Insulin secretion was normalized to low glucose stimulation, and insulin content was normalized to DNA mass.

\section{Insulin secretion analysis of KCNQ1R397W transfected mouse pancreatic $\beta$ cells}

The hKCNQ1 cDNA was subcloned into the pIRES2-AcGFP1 vector. We transfected the $K C N Q 1$ constructs and the empty vector into our established mouse pancreatic $\beta$ cells (referred to as SJ $\beta$ cells (Jia et al., 2015)) using AmaxaTM Cell Line NucleofectorTM Kit V and AmaxaTM NucleofectorTM 2b device (Lonza, Switzerland). The glucose-sensitive mouse $\beta$-cell line SJ- $\beta$ was cultured and an insulin-secretion assay performed as reported earlier (Jia et al., 2015). For control, cells were transfected with wild-type KCNQ1 or left untransfected. Insulin secreted into medium and from whole-cell lysates was quantified with Mouse High Range Insulin ELISA kit, according to manufacturer's protocol (Alpco, Salem, USA). Cells were incubated for 30 min with low $(3.3 \mathrm{mM})$ or high $(16.7 \mathrm{mM})$ glucose concentration, and $30 \mathrm{mM}$ of $\mathrm{KCl}$ to depolarize the cell membrane. We normalized secreted insulin by the total cellular insulin and total insulin was normalized by the total cell protein. The experiments were repeated four times with different patches of mouse $\beta$-cells. 


\section{Electrical activity analysis}

Organoids were treated with TrypLE (10X) to dissociate to single cells. The $5 \%$ Matrigel solution was prepared by diluting Matrigel in S7 media supplemented with CloneR. The cell pellet was re-suspended with $10 \mu \mathrm{L}$ cold $5 \%$ Matrigel after aspirating supernatant. $8 \mu \mathrm{L}$ cell suspension was dotted to recording electrodes avoiding ground electrodes and incubated $0.5 \mathrm{~h}$ in a $\mathrm{CO}_{2}$ incubator until cell attachment. $300 \mu \mathrm{L}$ S7 media supplemented with CloneR was added against the wall of the well. The electrical activity (Spike Detector) was recorded in Neural Spikes mode on MAESTRO Pro (AXION BIOSYSTEMS). The threshold-baseline of Spike Detector was set by using $3 \mathrm{mM}$ glucose.

\section{Cytoplasmic $\mathrm{Ca}^{2+}$ level measurement}

Human islet and hESC-derived differentiated organoids (approximately 20 organoids or human islets per well) were respectively plated into a 96-well black plate (ThermoFisher) coated with 1\% hESC-qualified Matrigel. After $24 \mathrm{~h}$, the wells were washed with prewarmed $\left(37^{\circ} \mathrm{C}\right) \mathrm{KRB}$ buffer containing $2.5 \mathrm{mM}$ glucose. The cell organoids were incubated with $50 \mu \mathrm{M} \mathrm{Ca}^{2+}$-sensitive fluorescent probe Fluo4-AM (Life Techbologies) in $2.5 \mathrm{mM}$ glucose KRB buffer for $45 \mathrm{~min}$ in a $37^{\circ} \mathrm{C}$ incubator. The plate was incubated further in a $37^{\circ} \mathrm{C}$ incubator for 15 min after washing with $2.5 \mathrm{mM}$ glucose KRB buffer. The plate was immediately staged on a Cell $R$ live Imaging System (Olympus) to acquire time-series imaging.

Fluo-4 AM was illuminated at using an excitation filter $492 / 18 \mathrm{~nm}$, and its emission was collected between 500-550 $\mathrm{nm}$. Time-series images were recorded at a resolution of $80 x$ magnification with a $20-\mathrm{sec}$ interval. The progression of glucose challenges and time of the stimulation during imaging was as follows: Imaging started after 5 min incubation in KRB buffer containing $2 \mathrm{mM}$ glucose and ran 16 cycles. The next step was followed by a 5 min incubation in KRB buffer containing $20 \mathrm{mM}$ glucose and ran 16 cycles. Sequential low and high glucose challenges were repeated one more time after washing with low glucose KRB buffer. The organoids' imaging was resumed after adding low or high glucose solution. Fluorescence intensity was measured by using Fiji software. StackReg was applied to anchor the organoids 
throughout the imaging. The positions of organoids were added to the ROI manager. The fluorescence intensity of the organoids was measured throughout the imaging. Finally, all of the fluorescence intensity of the same organoid was normalized to its first image.

\section{Electron Microscopy}

$\beta$-cell like organoids (day 31) were fixed in a freshly prepared mixture of $2 \%$ formaldehyde and $2 \%$ glutaraldehyde (Sigma) in $0.1 \mathrm{M}$ phosphate buffer $(18.2 \% 0.1$ $\mathrm{M} \mathrm{KH}_{2} \mathrm{PO}_{4}, 81.8 \% 0.1 \mathrm{M} \mathrm{Na}_{2} \mathrm{HPO}_{4}$ in $\mathrm{ddH}_{2} \mathrm{O}$ ) for $1 \mathrm{~h}$ at room temperature, followed by fixation at $4^{\circ} \mathrm{C}$ overnight. Samples were stained with $1 \% \mathrm{OsO}_{4}$ for $2 \mathrm{~h}$ after washing with $0.1 \mathrm{M}$ phosphate buffer. They were dehydrated in a graded ethanol series and propylene oxide and embedded in Poly/BedR 812 (Polysciences Inc.). Ultrathin sections were contrasted with uranyl acetate and lead citrate. Finally, sections were examined with a Morgagni electron microscope (Thermo Fisher). Digital images were taken with a Morada CCD camera and the iTEM software (EMSIS GmbH, Münster).

\section{RNA-seq and data analysis}

mRNA quality was checked by using Agilent 2100 Bioanalyzer following the protocol of RNA 6000 Nano Kit. BGI Hongkong prepared the DNA libraries and sequenced the libraries on a DNBseq Eukaryotic-T resequencing.

A 30 million 100 bp paired-end reads were obtained per sample. Discarding low-quality reads, trimming adaptor sequences, and eliminating poor-quality bases were done using FASTX-Toolkit and Trimmomatic. Building index and alignment, the reads were performed using Salmon after discarding outliers with over $30 \%$ disagreement. GC content and gene length biases were checked using $\mathrm{R}$ package NOISeq to quality control of count data. Mean-variance and PCA were calculated between biological replicates using the tximport package in $\mathrm{R}$. The parameters of lengthscaledTPM were CPM cutoff $>2$ and sample cutoff 2 between the replicates for the analyzed groups. The RUv package from Bioconductor was used to eliminate batch effects. Therefore, all of the samples were normalized to TMM (weighted trimmed mean of M-values). Gene counts were used for differential expression 
analysis using the EdgeR package (Table S5). The gene ontology enrichment was performed using ShinyGo v0.61(KEGG, FDR 0.1). The common genes from categories were selected and made heatmaps using the complexheatmap package from Bioconductor (Gu, Eils et al., 2016).

\section{Pro-apoptosis analysis}

Organoids were treated with TrypLE (10X) to dissociate to single cells and then washed with $1 \mathrm{~mL} 0.2 \%$ BSA. The cell pellet was re-suspended with $2 \mathrm{~mL} \mathrm{S7}$ media supplemented with CloneR. The cells were incubated in a $1 \%$ Matrigel coated plate for two days in a $37^{\circ} \mathrm{C}$ incubator. The flat culture cells were treated with TrypLE (10X) to dissociate to single cells and then washed with $1 \mathrm{~mL} 0.2 \%$ BSA. FITC Annexin V antibodies and 7-AAD were loaded into $100 \mu \mathrm{L}$ cells suspension aliquot to analyze pro-apoptosis following the manufacturer's instructions (BD Biosciences). FITC isotypes were used as the isotope control. Cells were suspended into $200 \mu \mathrm{L} 1 \mathrm{X}$ binding buffer after aspirating supernatant. One well of cells were treated with $200 \mu \mathrm{M}$ $\mathrm{H}_{2} \mathrm{O}_{2} 6 \mathrm{~h}$ as a positive apoptosis sample for compensation setting. The samples were analyzed on a flow cytometer after the compensation setting.

\section{Statistical analysis}

All qRT-PCR data were analyzed by the $\triangle \triangle$ Ct method. Data were analysed for normal distribution where applicable. Data were analyzed using unpaired/paired t-tests and one/two-way ANOVA. Dynamic $\mathrm{Ca}^{2+}$ flux was analyzed using two-way ANOVA and was generated with Prism8. The DNA sequence was visualized on Benchling. FlowJo was used to analyze Flow cytometry data. Immunofluorescence analysis was performed with Fiji. The intensity of protein on the PVDF membrane was analyzed with GelAnalyzer.

\section{Accession numbers}




\section{RNA-seq data are available from the GEO database under accession numbers} GSE168245. 


\section{Acknowledgements}

We thank Dr. Sebastian Diecke (MDC) for preliminary experiments in hiPSCs. We thank Prof. G. Abbott (University of California USA) providing the human KCNQ1 cDNA. We are grateful to Russell Hodge (MDC) for providing comments on the manuscript. We thank BioRender support the software for figure generation. We are also grateful to MDC for providing training grants. The staffs in the MDC facility are acknowledged for general maintenance and support. This work was supported by National Institutes of Health grants R01DK068471 and UG3DK122639 to M.S.

\section{Author Contributions}

Zhimin Zhou (zhouzhimin6@gmail.com) designed and conducted the overall experiments and analyzed the data of hESCs-derived samples and human islets, and cowrote the manuscript. Maolian Gong (Maolian_gong@yahoo.com) contributed to the family genetic analysis, supervised insulin secretion analysis of mouse SJ- $\beta$ cells. Amit Pande (Amit.Pande@mdc-berlin.de) contributed to the RNA-seq data. Ulrike Lisewski

(Lisewski@mdc-berlin.de) and Torsten Röpke (torsten.roepke@gmx.net) contributed to electrophysiology analysis in $\mathrm{CHO}$ cells. Bettina Purfürst (bettina.purfuerst@mdc-berlin.de) contributed to the generation of electron microscopy images. Lei Liang (ahl11980@hotmail.com) and Shiqi Jia (jshiqi@aliyun.com) contributed insulin secretion analysis of mouse SJ- $\beta$ cells. Sebastian Froehler (Bih-genomics@froehler.info) and Wei Chen (chenw@sustc.edu.cn) contributed to exome sequencing. Anca Margineanu (Anca.Margineanu@mdc-berlin.de) assisted in calcium signaling imaging. Chun Zeng (tzengchun@gmail.com) and Han Zhu (hazhu@ucsd.edu) provided advice on experimental design and hESC differentiation. Peter Kühnen (peter.kuehnen@charite.de),

Semik Khodaverdi (Semik_Khodaverdi@klinikum-hanau.de) and Winfried Krill (Winfried_Krill@klinikum-hanau.de) contributed to the clinical studies. Maike Sander (masander@ucsd.edu) supervised hESC differentiation into beta cells and provided 
comments on the manuscript. Klemens Raile (klemens.raile@charite.de) contribute to the clinical studies, funding acquisition and supervision. Zsuzsanna Izsvak (zizsvak@mdc-berlin.de) supervised the study, funding acquisition and cowrote the manuscript. Z.I., M.G. and K.R. generated the project. C.Z, H.Z, M.G. and K.R. provided comments and edits for the manuscript. All of the authors discussed the results and commented on the manuscript.

\section{Conflict of interest}

All authors declare that they have no conflict of interest. 


\section{Reference}

Neyroud N, Tesson F, Denjoy I, Leibovici M, Donger C, Barhanin J, Faure S, Gary F, Coumel P, Petit C, Schwartz K, Guicheney P (1997) A novel mutation in the potassium channel gene KVLQT1 causes the Jervell and Lange-Nielsen cardioauditory syndrome. Nat Genet 15: 186-9

Schroeder BC, Waldegger S, Fehr S, Bleich M, Warth R, Greger R, Jentsch TJ (2000) A constitutively open potassium channel formed by KCNQ1 and KCNE3. Nature 403: $196-9$

Waldegger S, Fakler B, Bleich M, Barth P, Hopf A, Schulte U, Busch AE, Aller SG, Forrest JN, Jr., Greger R, Lang F (1999) Molecular and functional characterization of s-KCNQ1 potassium channel from rectal gland of Squalus acanthias. Pflugers Arch 437: $298-304$

Kottgen M, Hoefer A, Kim SJ, Beschorner U, Schreiber R, Hug MJ, Greger R (1999)

Carbachol activates a $\mathrm{K}+$ channel of very small conductance in the basolateral membrane of rat pancreatic acinar cells. Pflugers Arch 438: 597-603

Barhanin J, Lesage F, Guillemare E, Fink M, Lazdunski M, Romey G (1996) $\mathrm{K}(\mathrm{V}) \mathrm{LQT} 1$ and IsK (minK) proteins associate to form the $\mathrm{I}(\mathrm{Ks})$ cardiac potassium current. Nature 384: 78-80

Chadha PS, Zunke F, Zhu HL, Davis AJ, Jepps TA, Olesen SP, Cole WC, Moffatt JD, Greenwood IA (2012) Reduced KCNQ4-encoded voltage-dependent potassium 
channel activity underlies impaired beta-adrenoceptor-mediated relaxation of renal arteries in hypertension. Hypertension 59: 877-84

Jepps TA, Chadha PS, Davis AJ, Harhun MI, Cockerill GW, Olesen SP, Hansen RS, Greenwood IA (2011) Downregulation of Kv7.4 channel activity in primary and secondary hypertension. Circulation 124: 602-11

Zeng H, Guo M, Zhou T, Tan L, Chong CN, Zhang T, Dong X, Xiang JZ, Yu AS, Yue L, Qi Q, Evans T, Graumann J, Chen S (2016) An Isogenic Human ESC Platform for Functional Evaluation of Genome-wide-Association-Study-Identified Diabetes Genes and Drug Discovery. Cell Stem Cel/ 19: 326-40

Chouabe C, Neyroud N, Guicheney P, Lazdunski M, Romey G, Barhanin J (1997) Properties of KvLQT1 K+ channel mutations in Romano-Ward and Jervell and Lange-Nielsen inherited cardiac arrhythmias. EMBO J 16: 5472-9

Sanguinetti MC, Curran ME, Zou A, Shen J, Spector PS, Atkinson DL, Keating MT (1996) Coassembly of K(V)LQT1 and minK (IsK) proteins to form cardiac I(Ks) potassium channel. Nature $384: 80-3$

Sachyani D, Dvir M, Strulovich R, Tria G, Tobelaim W, Peretz A, Pongs O, Svergun D, Attali B, Hirsch JA (2014) Structural basis of a Kv7.1 potassium channel gating module: studies of the intracellular c-terminal domain in complex with calmodulin.

Structure 22: 1582-94

MacDonald PE, Wheeler MB (2003) Voltage-dependent K(+) channels in pancreatic beta cells: role, regulation and potential as therapeutic targets. Diabetologia 46: 
Unoki H, Takahashi A, Kawaguchi T, Hara K, Horikoshi M, Andersen G, Ng DP, Holmkvist J, Borch-Johnsen K, Jorgensen T, Sandbaek A, Lauritzen T, Hansen T, Nurbaya S, Tsunoda T, Kubo M, Babazono T, Hirose H, Hayashi M, Iwamoto Y et al. (2008) SNPs in KCNQ1 are associated with susceptibility to type 2 diabetes in East Asian and European populations. Nat Genet 40: 1098-102

Yasuda K, Miyake K, Horikawa Y, Hara K, Osawa H, Furuta H, Hirota Y, Mori H, Jonsson A, Sato Y, Yamagata K, Hinokio Y, Wang HY, Tanahashi T, Nakamura N, Oka Y, Iwasaki N, Iwamoto Y, Yamada Y, Seino Y et al. (2008) Variants in KCNQ1 are associated with susceptibility to type 2 diabetes mellitus. Nat Genet 40: 1092-7 Chiou J, Zeng C, Cheng Z, Han JY, Schlichting M, Miller M, Mendez R, Huang S, Wang J, Sui Y, Deogaygay A, Okino ML, Qiu Y, Sun Y, Kudtarkar P, Fang R, PreissI S, Sander M, Gorkin DU, Gaulton KJ (2021) Single-cell chromatin accessibility identifies pancreatic islet cell type- and state-specific regulatory programs of diabetes risk. Nat Genet 53: 455-466

Thomas ER, Brackenridge A, Kidd J, Kariyawasam D, Carroll P, Colclough K, Ellard S (2016) Diagnosis of monogenic diabetes: 10-Year experience in a large multi-ethnic diabetes center. J Diabetes Investig 7: 332-7

Cho NH, Shaw JE, Karuranga S, Huang Y, da Rocha Fernandes JD, Ohlrogge AW, Malanda B (2018) IDF Diabetes Atlas: Global estimates of diabetes prevalence for 2017 and projections for 2045. Diabetes Res Clin Pract 138: 271-281 Hattersley AT, Patel KA (2017) Precision diabetes: learning from monogenic diabetes. Diabetologia 60: 769-777 
Grulich-Henn J, Wagner V, Thon A, Schober E, Marg W, Kapellen TM, Haberland H,

Raile K, Ellard S, Flanagan SE, Hattersley AT, Holl RW (2010) Entities and frequency of neonatal diabetes: data from the diabetes documentation and quality management system (DPV). Diabet Med 27: 709-12

Sanyoura M, Philipson LH, Naylor R (2018) Monogenic Diabetes in Children and Adolescents: Recognition and Treatment Options. Curr Diab Rep 18: 58

Polak M, Cave H (2007) Neonatal diabetes mellitus: a disease linked to multiple mechanisms. Orphanet J Rare Dis 2: 12

Aguilar-Bryan L, Bryan J (2008) Neonatal diabetes mellitus. Endocr Rev 29: 265-91

Mohora R, Stoicescu SM (2016) Congenital Diabetes Mellitus. Maedica (Buchar)11: $154-157$

Rorsman P, Ashcroft FM (2018) Pancreatic beta-Cell Electrical Activity and Insulin Secretion: Of Mice and Men. Physiol Rev 98: 117-214

Nakano S, Murakami K, Meguro M, Soejima H, Higashimoto K, Urano T, Kugoh H, Mukai T, Ikeguchi M, Oshimura M (2006) Expression profile of LIT1/KCNQ1OT1 and epigenetic status at the KvDMR1 in colorectal cancers. Cancer Sci 97: 1147-54

Asahara S, Etoh H, Inoue H, Teruyama K, Shibutani Y, Ihara Y, Kawada Y, Bartolome A, Hashimoto N, Matsuda T, Koyanagi-Kimura M, Kanno A, Hirota Y, Hosooka T, Nagashima K, Nishimura W, Inoue H, Matsumoto M, Higgins MJ, Yasuda K et al. (2015) Paternal allelic mutation at the Kcnq1 locus reduces pancreatic beta-cell mass by epigenetic modification of Cdkn1c. Proc Natl Acad Sci U S A 112: 8332-7 
Zhou T, Kim TW, Chong CN, Tan L, Amin S, Sadat Badieyan Z, Mukherjee S,

Ghazizadeh Z, Zeng H, Guo M, Crespo M, Zhang T, Kenyon R, Robinson CL,

Apostolou E, Wang H, Xiang JZ, Evans T, Studer L, Chen S (2018) A hPSC-based

platform to discover gene-environment interactions that impact human beta-cell and dopamine neuron survival. Nat Commun 9: 4815

Ghosh S, Nunziato DA, Pitt GS (2006) KCNQ1 assembly and function is blocked by long-QT syndrome mutations that disrupt interaction with calmodulin. Circ Res 98:

\section{$1048-54$}

Samani NJ, Erdmann J, Hall AS, Hengstenberg C, Mangino M, Mayer B, Dixon RJ, Meitinger T, Braund P, Wichmann HE, Barrett JH, Konig IR, Stevens SE, Szymczak S, Tregouet DA, Iles MM, Pahlke F, Pollard H, Lieb W, Cambien F et al. (2007) Genomewide association analysis of coronary artery disease. N Engl J Med 357: 443-53

Van Bergen NJ, Guo Y, Rankin J, Paczia N, Becker-Kettern J, Kremer LS, Pyle A, Conrotte JF, Ellaway C, Procopis P, Prelog K, Homfray T, Baptista J, Baple E, Wakeling M, Massey S, Kay DP, Shukla A, Girisha KM, Lewis LES et al. (2019) $\mathrm{NAD}(\mathrm{P}) \mathrm{HX}$ dehydratase (NAXD) deficiency: a novel neurodegenerative disorder exacerbated by febrile illnesses. Brain 142: 50-58

Malik MU, Nadir H, Jessop ZM, Cubitt JJ (2020) Cutaneous manifestations of NAXD deficiency - A case report. Ann Med Surg (Lond) 60: 352-355

Boini KM, Graf D, Hennige AM, Koka S, Kempe DS, Wang K, Ackermann TF, Foller M, Vallon V, Pfeifer K, Schleicher E, Ullrich S, Haring HU, Haussinger D, Lang F 
(2009) Enhanced insulin sensitivity of gene-targeted mice lacking functional KCNQ1. Am J Physiol Regul Integr Comp Physio/ 296: R1695-701

Aylward A, Chiou J, Okino ML, Kadakia N, Gaulton KJ (2018) Shared genetic risk contributes to type 1 and type 2 diabetes etiology. Hum Mol Genet

Wang X, Cahill CM, Pineyro MA, Zhou J, Doyle ME, Egan JM (1999) Glucagon-like peptide-1 regulates the beta cell transcription factor, PDX-1, in insulinoma cells. Endocrinology 140: 4904-7

Wang X, Zhou J, Doyle ME, Egan JM (2001) Glucagon-like peptide-1 causes pancreatic duodenal homeobox-1 protein translocation from the cytoplasm to the nucleus of pancreatic beta-cells by a cyclic adenosine monophosphate/protein kinase A-dependent mechanism. Endocrinology 142: 1820-7

Xie R, Everett LJ, Lim HW, Patel NA, Schug J, Kroon E, Kelly OG, Wang A, D'Amour KA, Robins AJ, Won KJ, Kaestner KH, Sander M (2013) Dynamic chromatin remodeling mediated by polycomb proteins orchestrates pancreatic differentiation of human embryonic stem cells. Cell Stem Cel/ 12: 224-37

Jia S, Ivanov A, Blasevic D, Muller T, Purfurst B, Sun W, Chen W, Poy MN, Rajewsky N, Birchmeier C (2015) Insm1 cooperates with Neurod1 and Foxa2 to maintain mature pancreatic beta-cell function. EMBO J 34: 1417-33

Wiener R, Haitin Y, Shamgar L, Fernandez-Alonso MC, Martos A, Chomsky-Hecht O, Rivas G, Attali B, Hirsch JA (2008) The KCNQ1 (Kv7.1) COOH terminus, a multitiered scaffold for subunit assembly and protein interaction. J Bio/ Chem 283: 5815-30 
Sun J, MacKinnon R (2017) Cryo-EM Structure of a KCNQ1/CaM Complex Reveals Insights into Congenital Long QT Syndrome. Cel/ 169: 1042-1050 e9

Crotti L, Tester DJ, White WM, Bartos DC, Insolia R, Besana A, Kunic JD, Will ML, Velasco EJ, Bair JJ, Ghidoni A, Cetin I, Van Dyke DL, Wick MJ, Brost B, Delisle BP, Facchinetti F, George AL, Schwartz PJ, Ackerman MJ (2013) Long QT syndrome-associated mutations in intrauterine fetal death. JAMA 309: 1473-82

Busch AE, Suessbrich H, Waldegger S, Sailer E, Greger R, Lang H, Lang F, Gibson KJ, Maylie JG (1996) Inhibition of IKs in guinea pig cardiac myocytes and guinea pig IsK channels by the chromanol 293B. Pflugers Arch 432: 1094-6

Bleich M, Briel M, Busch AE, Lang HJ, Gerlach U, Gogelein H, Greger R, Kunzelmann K (1997) KVLQT channels are inhibited by the K+ channel blocker 293B. Pflugers Arch 434: 499-501

Wilson AJ, Quinn KV, Graves FM, Bitner-Glindzicz M, Tinker A (2005) Abnormal KCNQ1 trafficking influences disease pathogenesis in hereditary long QT syndromes (LQT1). Cardiovasc Res 67: 476-86

Schmitt N, Calloe K, Nielsen NH, Buschmann M, Speckmann EJ, Schulze-Bahr E, Schwarz M (2007) The novel C-terminal KCNQ1 mutation M520R alters protein trafficking. Biochem Biophys Res Commun 358: 304-10

Pagliuca FW, Millman JR, Gurtler M, Segel M, Van Dervort A, Ryu JH, Peterson QP, Greiner D, Melton DA (2014) Generation of functional human pancreatic beta cells in vitro. Cel/ 159: 428-39 
Dunn MF (2005) Zinc-ligand interactions modulate assembly and stability of the insulin hexamer -- a review. Biometals 18: 295-303

Deconinck JF, Potvliege PR, Gepts W (1971) The ultrasturcture of the human pancreatic islets. I. The islets of adults. Diabetologia 7: 266-82

Siengdee P, Trakooljul N, Murani E, Schwerin M, Wimmers K, Ponsuksili S (2015) MicroRNAs Regulate Cellular ATP Levels by Targeting Mitochondrial Energy Metabolism Genes during C2C12 Myoblast Differentiation. PLoS One 10: e0127850 Hwang HJ, Lynn SG, Vengellur A, Saini Y, Grier EA, Ferguson-Miller SM, LaPres JJ (2015) Hypoxia Inducible Factors Modulate Mitochondrial Oxygen Consumption and Transcriptional Regulation of Nuclear-Encoded Electron Transport Chain Genes. Biochemistry 54: 3739-48

Ikeda K, Shiba S, Horie-Inoue K, Shimokata K, Inoue S (2013) A stabilizing factor for mitochondrial respiratory supercomplex assembly regulates energy metabolism in muscle. Nat Commun 4: 2147

Haythorne E, Rohm M, van de Bunt M, Brereton MF, Tarasov Al, Blacker TS, Sachse G, Silva Dos Santos M, Terron Exposito R, Davis S, Baba O, Fischer R, Duchen MR, Rorsman P, MacRae JI, Ashcroft FM (2019) Diabetes causes marked inhibition of mitochondrial metabolism in pancreatic beta-cells. Nat Commun 10: 2474

Fu Z, Gilbert ER, Liu D (2013) Regulation of insulin synthesis and secretion and pancreatic Beta-cell dysfunction in diabetes. Curr Diabetes Rev 9: 25-53

Wente W, Efanov AM, Brenner M, Kharitonenkov A, Koster A, Sandusky GE, Sewing S, Treinies I, Zitzer H, Gromada J (2006) Fibroblast growth factor-21 improves 
pancreatic beta-cell function and survival by activation of extracellular signal-regulated kinase $1 / 2$ and Akt signaling pathways. Diabetes 55: 2470-8 Miralles F, Czernichow P, Ozaki K, Itoh N, Scharfmann R (1999) Signaling through fibroblast growth factor receptor $2 \mathrm{~b}$ plays a key role in the development of the exocrine pancreas. Proc Natl Acad Sci U S A 96: 6267-72

Hart AW, Baeza N, Apelqvist A, Edlund H (2000) Attenuation of FGF signalling in mouse beta-cells leads to diabetes. Nature 408: $864-8$

Sladek FM, Zhong WM, Lai E, Darnell JE, Jr. (1990) Liver-enriched transcription factor HNF-4 is a novel member of the steroid hormone receptor superfamily. Genes Dev 4: 2353-65

Miquerol L, Lopez S, Cartier N, Tulliez M, Raymondjean M, Kahn A (1994) Expression of the L-type pyruvate kinase gene and the hepatocyte nuclear factor 4 transcription factor in exocrine and endocrine pancreas. J Biol Chem 269: 8944-51

Twaroski K, Mallanna SK, Jing R, DiFurio F, Urick A, Duncan SA (2015) FGF2 mediates hepatic progenitor cell formation during human pluripotent stem cell differentiation by inducing the WNT antagonist NKD1. Genes Dev 29: 2463-74 Narla ST, Lee YW, Benson CA, Sarder P, Brennand KJ, Stachowiak EK, Stachowiak MK (2017) Common developmental genome deprogramming in schizophrenia - Role of Integrative Nuclear FGFR1 Signaling (INFS). Schizophr Res 185: 17-32 Kuo CJ, Conley PB, Chen L, Sladek FM, Darnell JE, Jr., Crabtree GR (1992) A transcriptional hierarchy involved in mammalian cell-type specification. Nature 355: 
Gerrish K, Cissell MA, Stein R (2001) The role of hepatic nuclear factor 1 alpha and PDX-1 in transcriptional regulation of the pdx-1 gene. J Biol Chem 276: 47775-84

Sansbury FH, Flanagan SE, Houghton JA, Shuixian Shen FL, AI-Senani AM, Habeb AM, Abdullah M, Kariminejad A, Ellard S, Hattersley AT (2012) SLC2A2 mutations can cause neonatal diabetes, suggesting GLUT2 may have a role in human insulin secretion. Diabetologia 55: 2381-5

De Vos A, Heimberg H, Quartier E, Huypens P, Bouwens L, Pipeleers D, Schuit F (1995) Human and rat beta cells differ in glucose transporter but not in glucokinase gene expression. J Clin Invest 96: 2489-95

Robertson RP, Harmon J, Tran PO, Tanaka Y, Takahashi H (2003) Glucose toxicity in beta-cells: type 2 diabetes, good radicals gone bad, and the glutathione connection.

\section{Diabetes 52: 581-7}

Bernal-Mizrachi E, Cras-Meneur C, Ye BR, Johnson JD, Permutt MA (2010)

Transgenic overexpression of active calcineurin in beta-cells results in decreased beta-cell mass and hyperglycemia. PLoS One 5: e11969

Kato I, Oya T, Suzuki H, Takasawa K, Ichsan AM, Nakada S, Ishii Y, Shimada Y, Sasahara M, Tobe K, Takasawa S, Okamoto H, Hiraga K (2008) A novel model of insulin-dependent diabetes with renal and retinal lesions by transgenic expression of CaMKIlalpha (Thr286Asp) in pancreatic beta-cells. Diabetes Metab Res Rev 24: $486-97$

Epstein PN, Overbeek PA, Means AR (1989) Calmodulin-induced early-onset diabetes in transgenic mice. Cel/58: 1067-73 
Zhang H, Zeitz MJ, Wang H, Niu B, Ge S, Li W, Cui J, Wang G, Qian G, Higgins MJ, Fan X, Hoffman AR, Hu JF (2014) Long noncoding RNA-mediated intrachromosomal interactions promote imprinting at the Kcnq1 locus. J Cell Bio/204: 61-75

Ong CT, Corces VG (2014) CTCF: an architectural protein bridging genome topology and function. Nat Rev Genet 15: 234-46

Sams DS, Nardone S, Getselter D, Raz D, Tal M, Rayi PR, Kaphzan H, Hakim O, Elliott E (2016) Neuronal CTCF Is Necessary for Basal and Experience-Dependent Gene Regulation, Memory Formation, and Genomic Structure of BDNF and Arc. Cell $\operatorname{Rep~17:~2418-2430~}$

Tang M, Chen B, Lin T, Li Z, Pardo C, Pampo C, Chen J, Lien CL, Wu L, Ai L, Wang H, Yao K, Oh SP, Seto E, Smith LE, Siemann DW, Kladde MP, Cepko CL, Lu J (2011) Restraint of angiogenesis by zinc finger transcription factor CTCF-dependent chromatin insulation. Proc Natl Acad Sci U S A 108: 15231-6

Soshnikova N, Montavon T, Leleu M, Galjart N, Duboule D (2010) Functional analysis of CTCF during mammalian limb development. Dev Cel/ 19: 819-30

Welsh IC, Kwak H, Chen FL, Werner M, Shopland LS, Danko CG, Lis JT, Zhang M, Martin JF, Kurpios NA (2015) Chromatin Architecture of the Pitx2 Locus Requires CTCF- and Pitx2-Dependent Asymmetry that Mirrors Embryonic Gut Laterality. Cell Rep 13: 337-49

Li Y, Gao J, Lu Z, McFarland K, Shi J, Bock K, Cohen IS, Cui J (2013) Intracellular ATP binding is required to activate the slowly activating $\mathrm{K}+$ channel $\mathrm{I}(\mathrm{Ks})$. Proc Nat/ Acad Sci U S A 110: 18922-7 
Fridlyand LE, Jacobson DA, Philipson LH (2013) Ion channels and regulation of insulin secretion in human beta-cells: a computational systems analysis. Is/ets 5: 1-15 Murakami T, Ockinger J, Yu J, Byles V, McColl A, Hofer AM, Horng T (2012) Critical role for calcium mobilization in activation of the NLRP3 inflammasome. Proc Nat/ Acad Sci U S A 109: 11282-7

Rossol M, Pierer M, Raulien N, Quandt D, Meusch U, Rothe K, Schubert K, Schoneberg T, Schaefer M, Krugel U, Smajilovic S, Brauner-Osborne H, Baerwald C, Wagner U (2012) Extracellular Ca2+ is a danger signal activating the NLRP3 inflammasome through $\mathrm{G}$ protein-coupled calcium sensing receptors. Nat Commun 3: 1329

Kapplinger JD, Tester DJ, Salisbury BA, Carr JL, Harris-Kerr C, Pollevick GD, Wilde AA, Ackerman MJ (2009) Spectrum and prevalence of mutations from the first 2,500 consecutive unrelated patients referred for the FAMILION long QT syndrome genetic test. Heart Rhythm 6: 1297-303

Bellocq C, van Ginneken AC, Bezzina CR, Alders M, Escande D, Mannens MM, Baro I, Wilde AA (2004) Mutation in the KCNQ1 gene leading to the short QT-interval syndrome. Circulation 109: 2394-7

Torekov SS, lepsen E, Christiansen M, Linneberg A, Pedersen O, Holst JJ, Kanters JK, Hansen T (2014) KCNQ1 long QT syndrome patients have hyperinsulinemia and symptomatic hypoglycemia. Diabetes 63: 1315-25 
Finol-Urdaneta RK, Remedi MS, Raasch W, Becker S, Clark RB, Struver N, Pavlov E,

Nichols CG, French RJ, Terlau H (2012) Block of Kv1.7 potassium currents increases glucose-stimulated insulin secretion. EMBO Mol Med 4: 424-34

Richardson CD, Ray GJ, DeWitt MA, Curie GL, Corn JE (2016) Enhancing

homology-directed genome editing by catalytically active and inactive CRISPR-Cas 9 using asymmetric donor DNA. Nat Biotechno/34: 339-44

Gu Z, Eils R, Schlesner M (2016) Complex heatmaps reveal patterns and correlations in multidimensional genomic data. Bioinformatics 32: 2847-9 
A
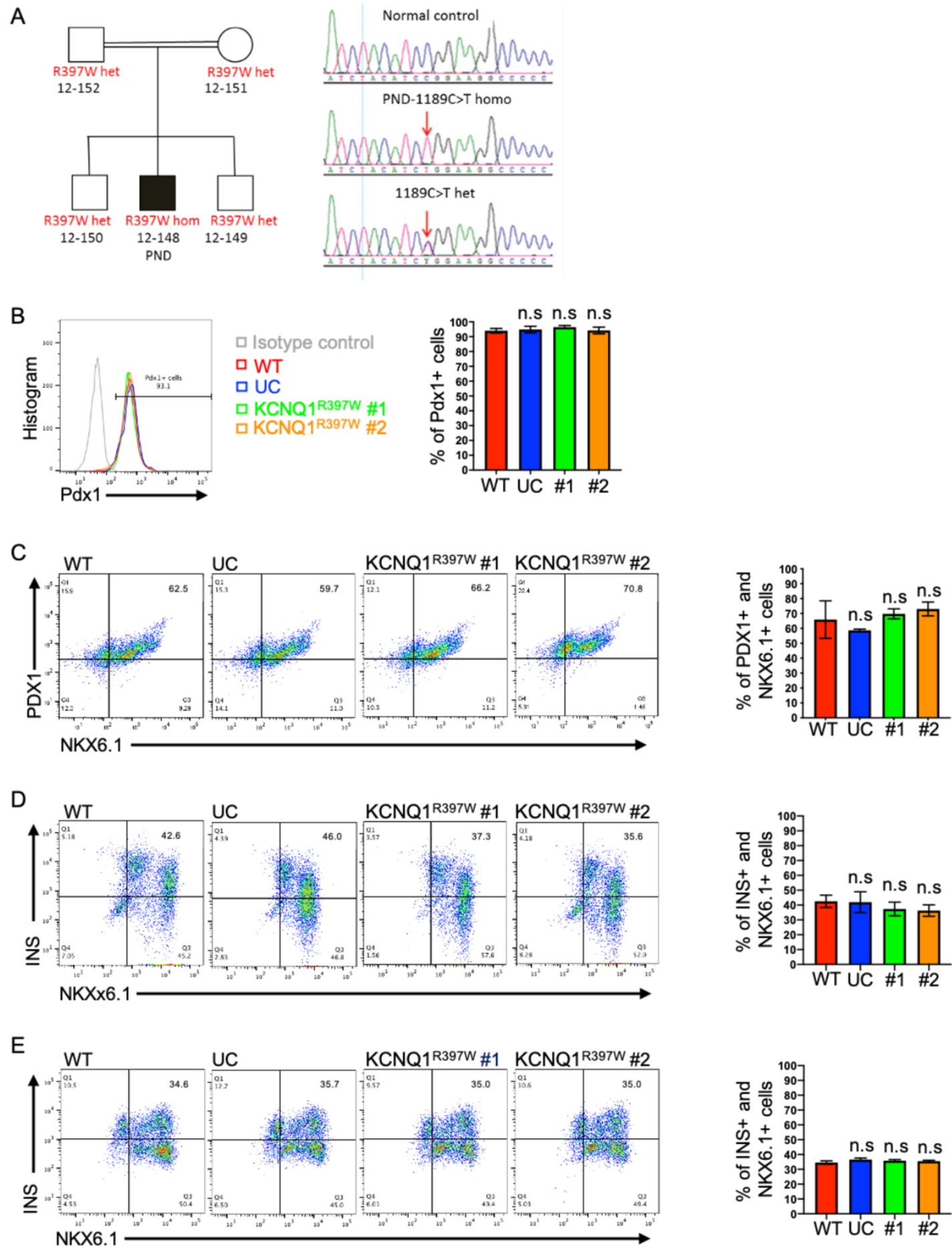

Figure 1. KCNQ1 R397W hESCs normally differentiated to human $\beta$-like cells.

A. Pedigree of the patient's family. Squares and circles represent males and females,

respectively. The patient (marked in black) diagnosed by permanent neonatal diabetes (PND).

Other members of his family are healthy. The region of the $1189 \mathrm{C}>\mathrm{T}$ mutation in KCNQ1 is 
shown from control; homozygous (homo) mutation from the patient; patient's family members (heterozygous).

B-E. Flow cytometry analysis and quantification of cells using stage-specific markers.

Pancreatic endoderm cells (day 11) express PDX1 (B). Pancreatic endocrine precursor cells

(day 14) express PDX1 and NKX6.1 (C). Immature $\beta$ cells (day 21) express NKX6.1 and

insulin (INS) (D). Matured $\beta$ cells (day 31) express NKX6.1 and insulin (E).

Data information: In (B-E), data are presented as mean \pm SD. n.s indicates a non-significant difference, ${ }^{*} p<0.05,{ }^{* *} p<0.01,{ }^{* * *} p<0.001$, and ${ }^{* * *} p<0.0001$ (Student's t-test). 
bioRxiv preprint doi: https://doi. org/10.1101/2021.08 24 457485. this version posted August 26, 2021. The copyright holder for this preprint (which was not certified by peer review) is the author/funder, who has granted bioRxiv a license to display the preprint in perpetuity. It is made available under aCC-BY-NC-ND 4.0 International license.
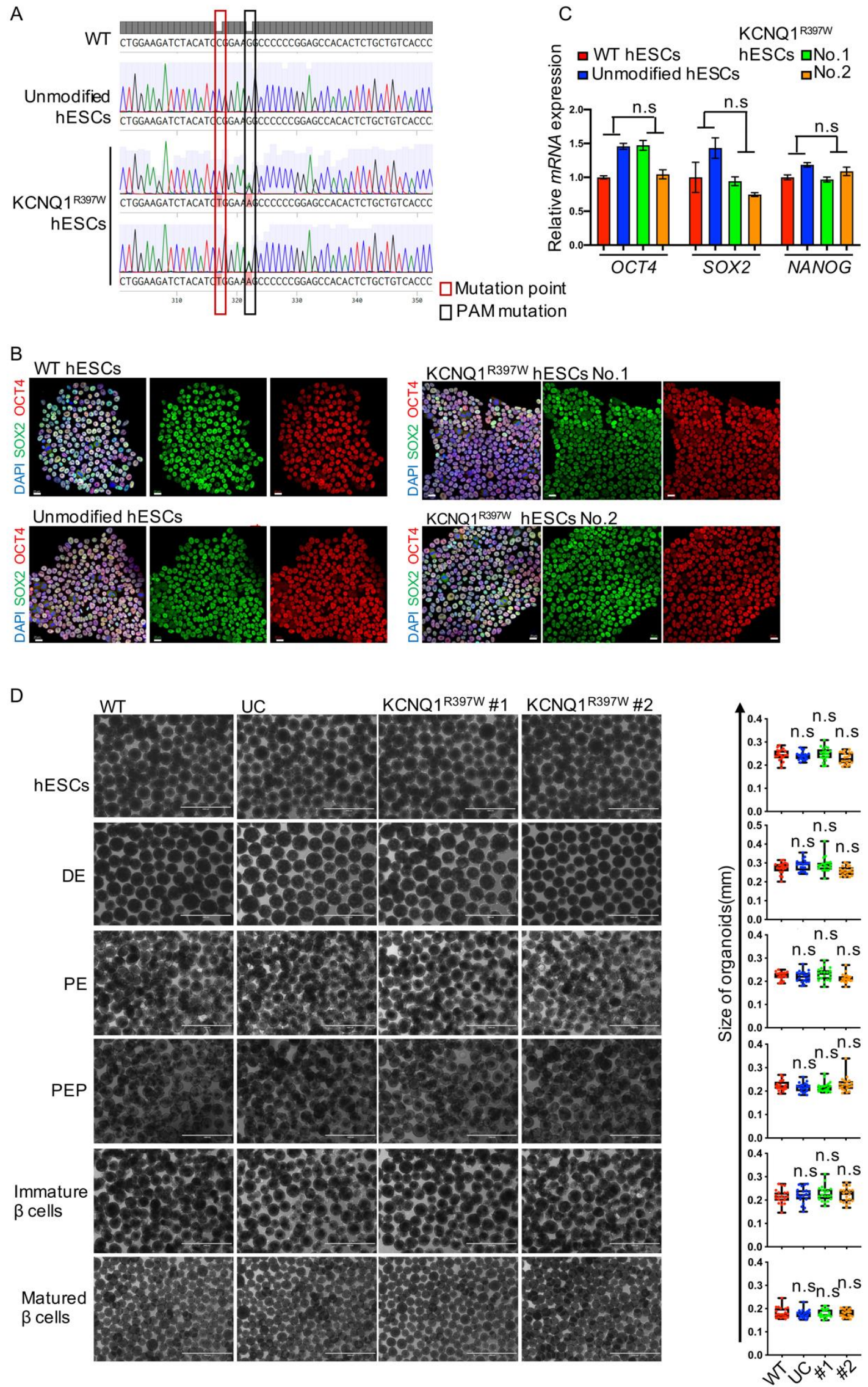
Figure EV1. In vitro generation of the permanent neonatal diabetes (PND) patient-derived KCNQ1 mutation (1189 C>T) in human $\beta$-like cells.

A. Sanger sequencing of CRISPR/Cas9 edited KCNQ1R397W mutation in hESCs (red box).

PAM, protospacer adjacent motif (black box).

B. Immunostaining of WT, UC and KCNQ1 ${ }^{R 397 W}$ hESCs using pluripotency markers SOX2 and OCT4. Scale bar $=20 \mu \mathrm{m}$.

C. Characterization of WT, unmodified control (UC), and KCNQ1R397W hESCs by qRT-PCR, specific for pluripotency markers (OCT4, SOX2, and NANOG). Data are normalized to $G A P D H$ and presented as mean $\pm \mathrm{SD}$.

D. Cell morphology at different stages of the differentiation, including the stage of hESCs (day 0 ), definitive endoderm ( $D E$, day 3), pancreatic endoderm (PE, day 11), pancreatic endocrine precursors (PEP, day 14), immature $\beta$ cells (day 21), and matured $\beta$ cells (day 31 ). Scale bar=1 $\mathrm{mm}$.

Data information: In ( $C$ and $D)$, data are presented as mean \pm SD. n.s indicates a non-significant difference, ${ }^{*} p<0.05,{ }^{* *} p<0.01,{ }^{* * *} p<0.001$, and ${ }^{* * *} p<0.0001$ (Student's t-test). 
A

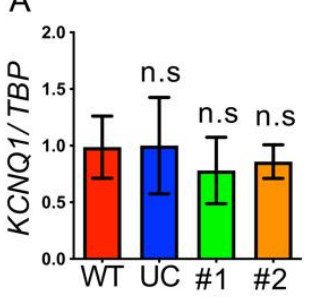

C

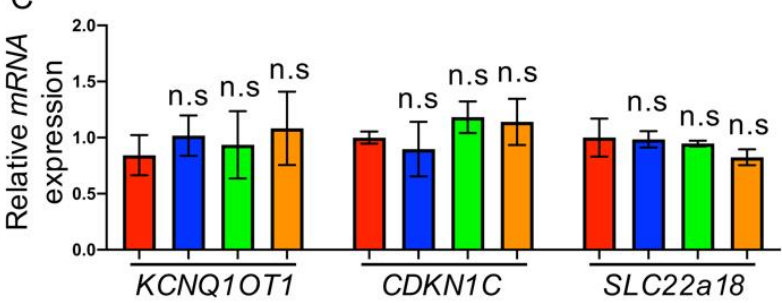

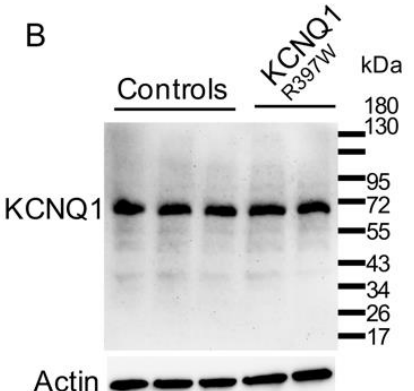

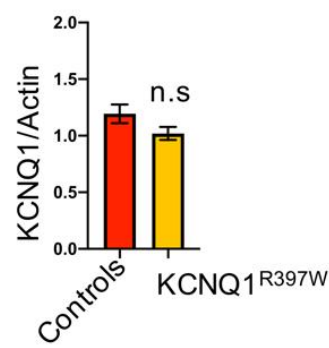

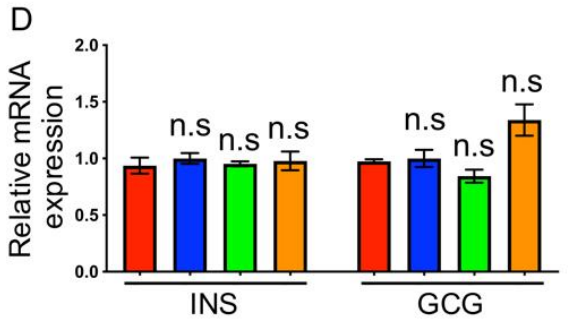

$E$

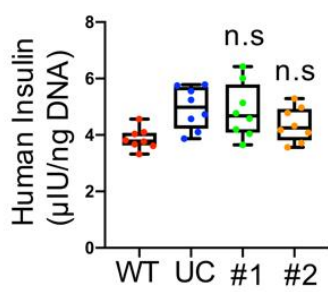

$\mathrm{F}$
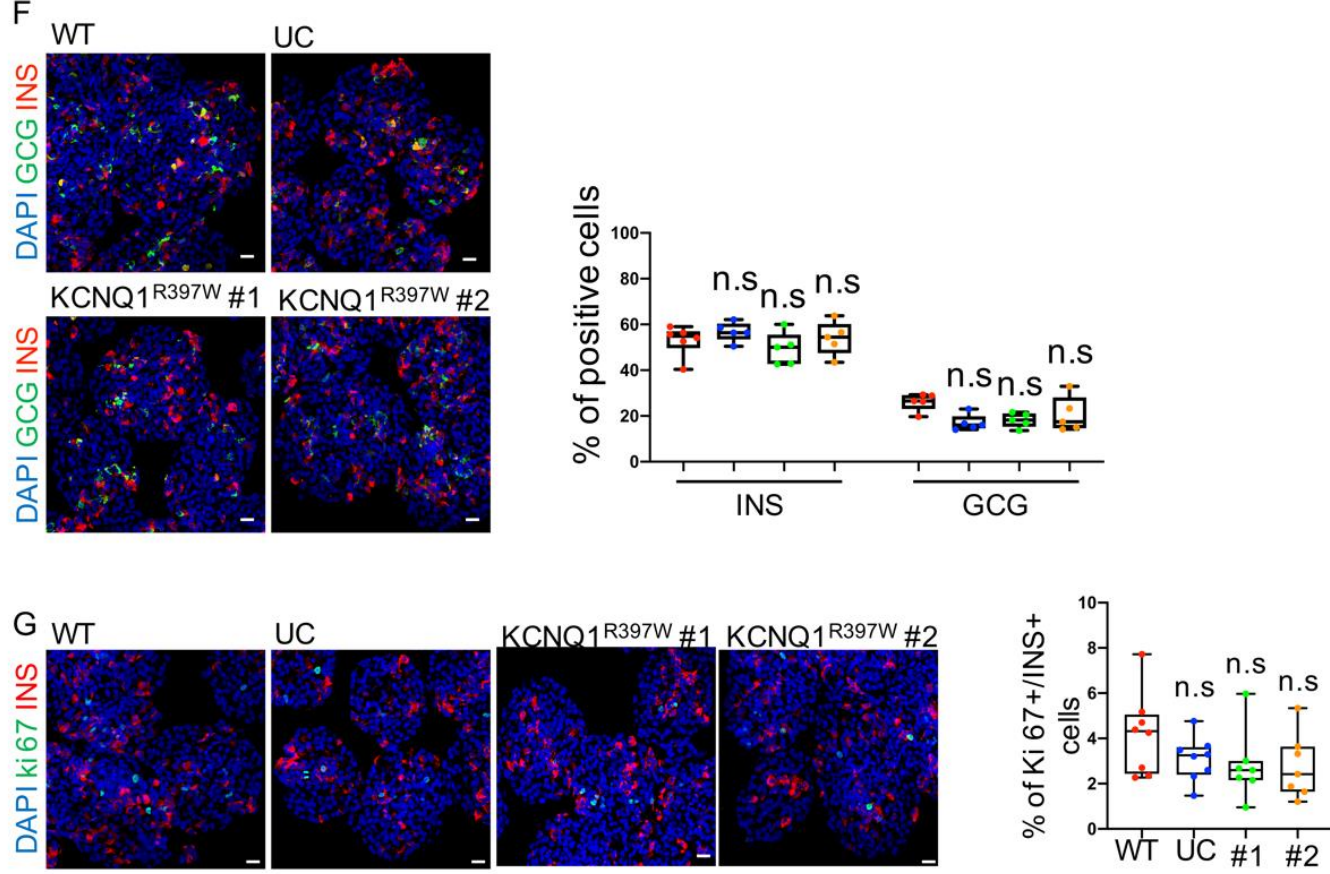

Figure 2. The $1189 \mathrm{C}>\mathrm{T}$ mutation did not affect regulatory genomics.

A. The KCNQ1 mRNA level was analyzed by qRT-PCR in human day 31 organoids of WT,

UC, and KCNQ1R397W. 
B. Western blot analysis and quantification of KCNQ1 expression in human day 31 organoids of controls (WT and UC) and KCNQ1R397W. Data are normalized to ACTIN.

C. q-PCR analysis of the expressions of KCNQ1OT1, CDKN1C, and SLC22a18 at human day 31 organoids.

D. Pancreatic islet-like organoids from WT, UC, and KCNQ1 R397W were characterized by qRT-PCR, using glucagon ${ }^{+}\left(\mathrm{GCG}^{+}\right)$and insulin+ ${ }^{+}$INS +$)$as $\alpha-$ and $\beta$ cell-specific markers, respectively.

E. Total insulin content per 1ng DNA of insulin+ cells between KCNQ1R397W and controls matured $\beta$-like cells (day 31).

F. Immunostaining and quantification INS+ and GCG+ cells at day 31 (matured $\beta$ cells).

G. Immunostaining and quantification of Ki67+ in $\beta$-like cells. Scale bar=20 $\mu \mathrm{m}$. qPCR data are normalized to housekeeping gene TBP(TATA-Box Binding Protein).

Data information: Scale bar $=20 \mu \mathrm{m}(\mathrm{F}$ and $\mathrm{G})$. Data are presented as mean \pm SD. n.s indicates a non-significant difference, ${ }^{*} p<0.05,{ }^{* *} p<0.01,{ }^{* * *} p<0.001$, and ${ }^{* * * *} p<0.0001$ (Student's t-test). 
bioRxiv preprint doi: https://doi org/101101/2021.08 24 457485- this version posted August 26, 2021. The copyright holder for this preprint (which was not certified by peer review) is the author/funder, who has granted bioRxiv a license to display the preprint in perpetuity. It is made available under aCC-BY-NC-ND 4.0 International license.

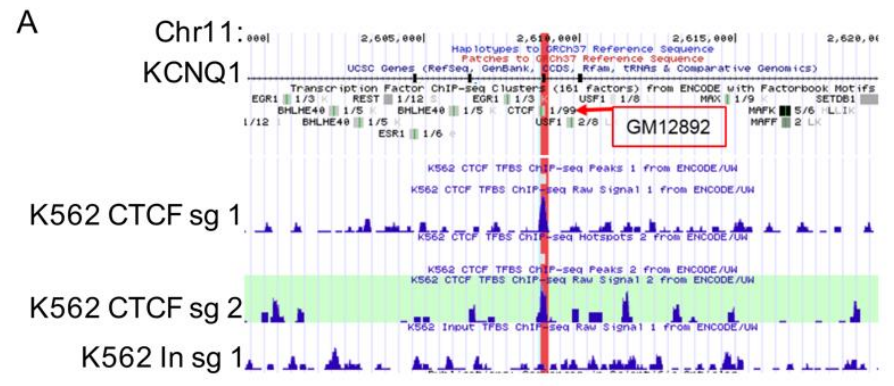

B

RefSeq genes

hESC H3K27ac

DE H3K27ac

PGT H3K27ac

PE H3K27ac

C

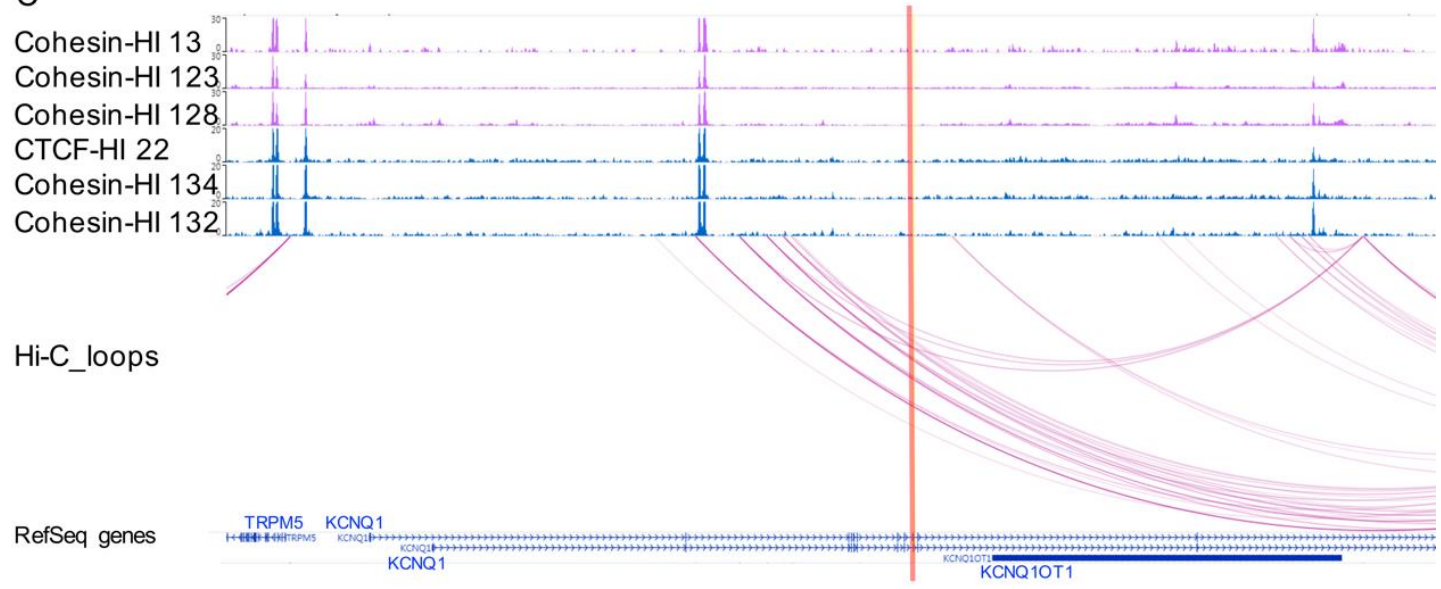

D

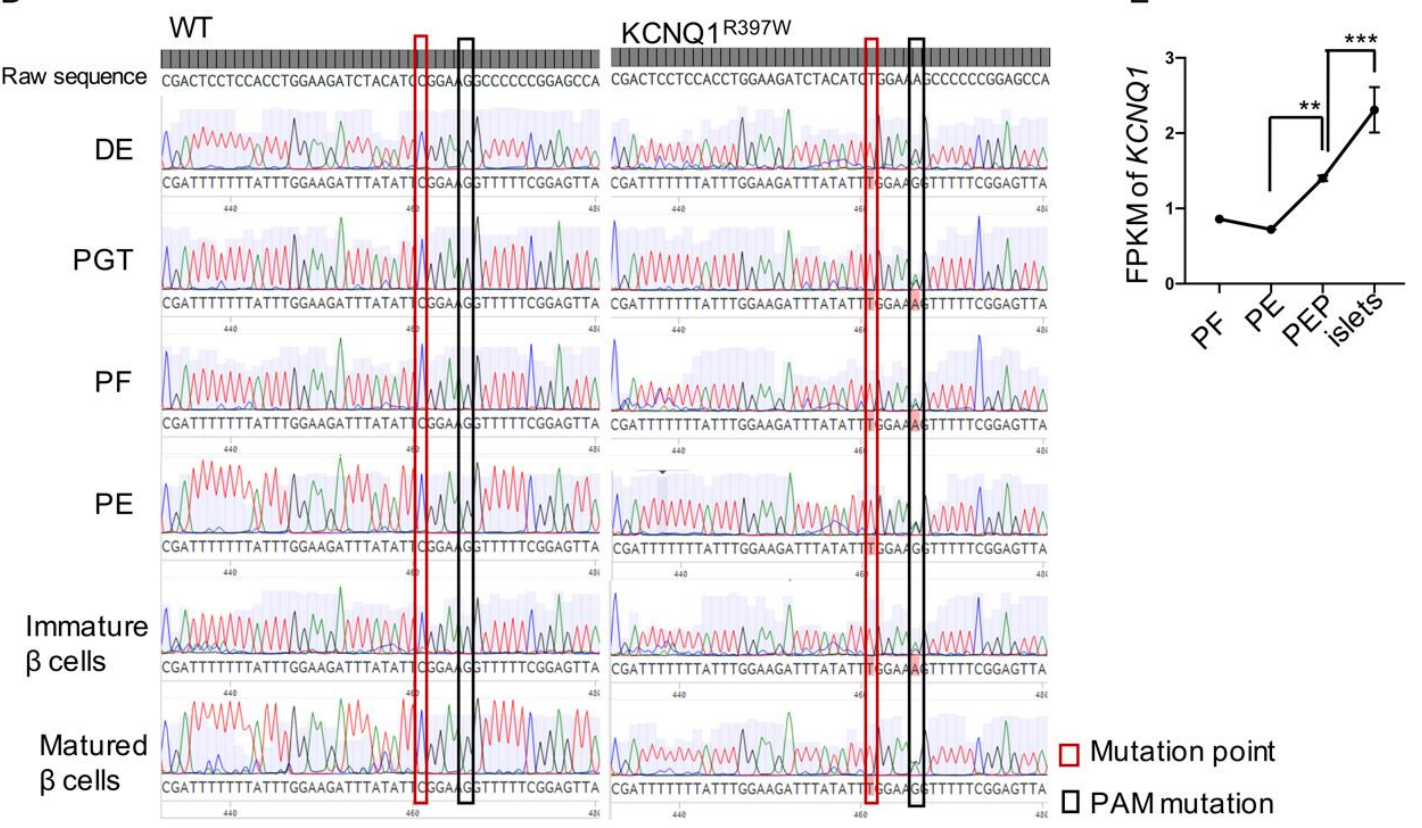

Figure EV2. Regulatory genomics of the C1189T mutation of KCNQ1. 
A. The CTCF binding signal in KCNQ1 locus showed by UCSC Genome Browser. Tracks show signals of CTCF binding (potential CTCF binding motif) in cell lines: GM12892 (human B-lymphocyte, lymphoblastoid and K562 (human myelogenous leukemia).

B. The dynamic enhancer signal during $\beta$-cell differentiation is revealed by H3K27ac CHIP assay(Xie et al., 2013) in hESCs, DE, primitive gut tube (PGT), and PE. The potential enhancer is highlighted in light green.

C. Cohesin and CTCF binding (ChIP) signals and the predicted chromatin loops at the KCNQ1 gene and its neighboring genomic region in human islets (Hi-C data(Miguel-Escalada et al., 2019)).

D. Cytosine methylation analysis in different stages of differentiation, including DE, PGT, posterior foregut (PF), PE, immature $\beta$ cells and matured $\beta$ cells. The C1189T mutation is boxed in red, whereas the PAM mutation marked by black.

E. FPKM (Fragments per kilobase of transcript per million mapped reads) levels of $K C N Q 1$ transcripts during human pancreatic differentiation, in PF, PE, PEP and matured islets after transplanted into mice(Xie et al., 2013). Data presented as mean \pm SD. n.s indicates a non-significant difference, ${ }^{*} p<0.05,{ }^{* *} p<0.01,{ }^{* * *} p<0.001$, and ${ }^{* * *} p<0.0001$ (one-way ANOVA).

Data information: In (A-C), the position of the C1189T mutation in exon 9 of KCNQ1 is marked by a red bar. 


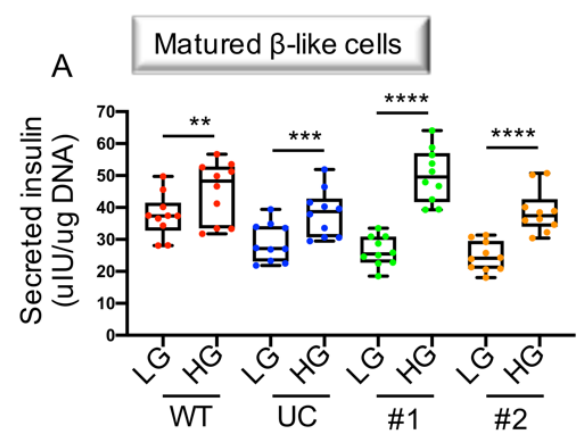

C
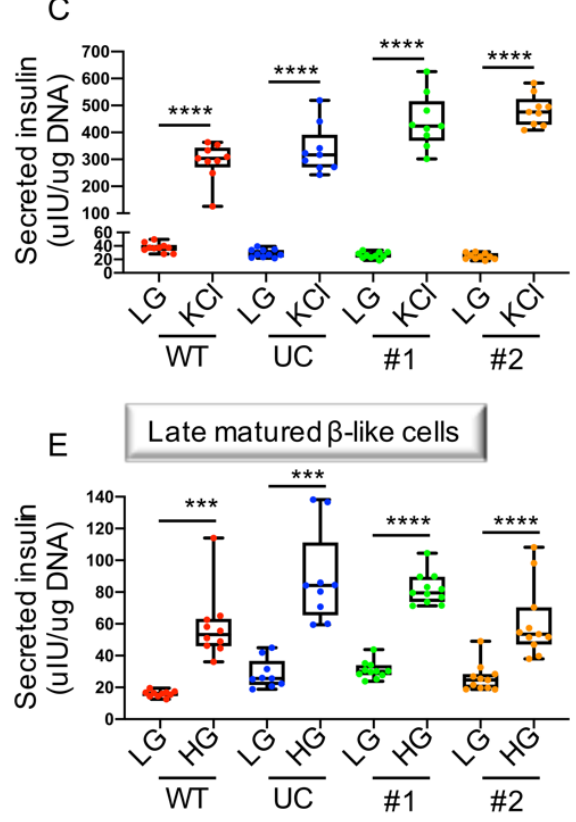

G

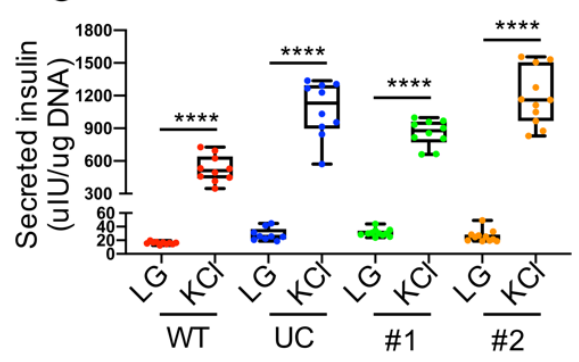

B

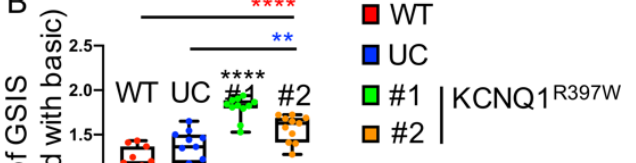

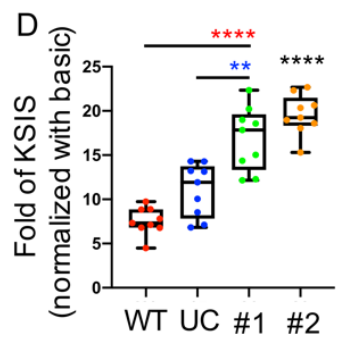
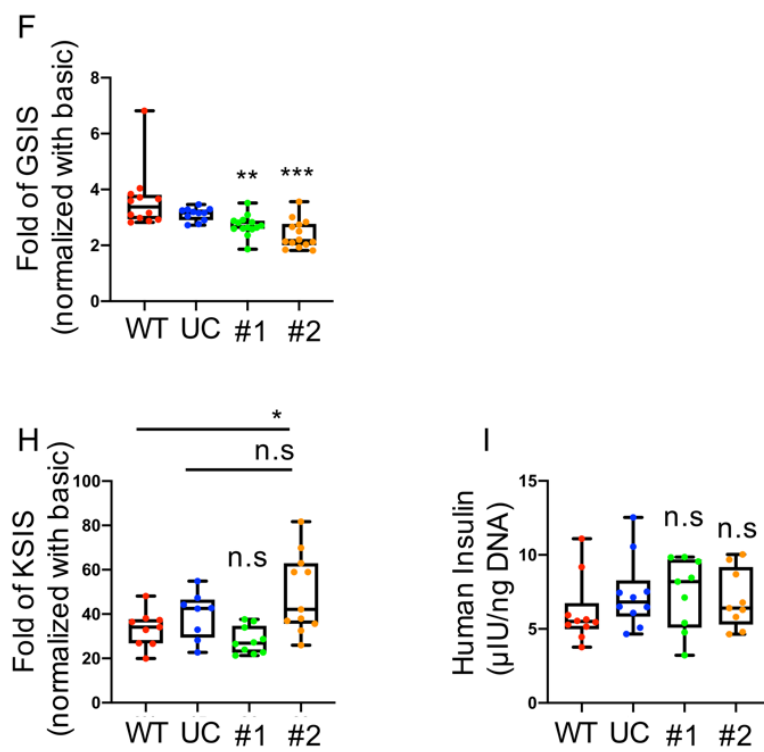

Figure 3. Time/stage-dependent insulin secretion of human $\beta$-like cells (day 31 or day 40 )

upon various challenges, derived from KCNQ1 R397W \#1, \#2, unmodified hESCs (UC) and WT

hESCs (WT).

A-H. the content of insulin secretion per 1ng DNA of insulin+ cells (Left panels). fold-change of insulin secretion upon various stimulations (Right panels). Day 31 (A and B) and day 40 ( $E$ and 
F) human $\beta$-like cells upon $16.8 \mathrm{mM}$ glucose stimulation (GSIS). Day 31 (C and D) and day40

( $\mathrm{G}$ and $\mathrm{H}$ ) human $\beta$-like cells upon $30 \mathrm{mM} \mathrm{KCl}$ stimulation (KSIS).

I. Total insulin content per $1 \mathrm{ng}$ DNA of insulin+ cells between KCNQ1 ${ }^{\mathrm{R} 397 \mathrm{~W}}$ and controls

late-stage $\beta$-like cells (day 40).

Data information: Data are presented as mean \pm SD. n.s indicates a non-significant difference,

${ }^{*} \mathrm{p}<0.05,{ }^{* *} \mathrm{p}<0.01,{ }^{* * *} \mathrm{p}<0.001$, and ${ }^{* * *} \mathrm{p}<0.0001$ (Student's t-test).

$\mathrm{A} \quad-\mathrm{UC}$

${ }^{-}$KCNQ1 R397W

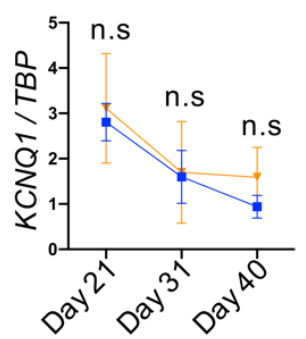

C

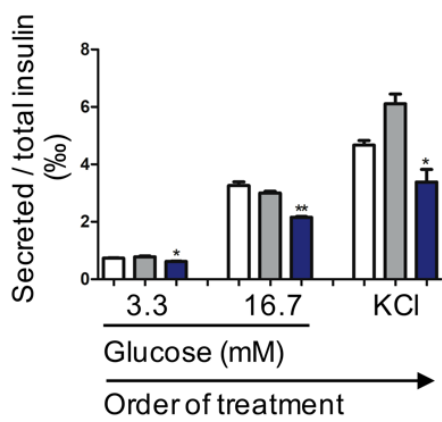

B Maturing $\beta$-like cells

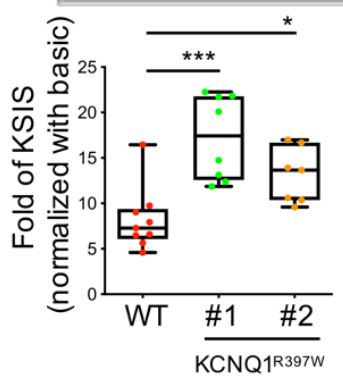

Figure EV3. The insulin secretion of human day 28 organoids and KCNQ1 ${ }^{R 397 W}$ transfected mouse SJ $\beta$ cells upon stimulation.

A. qRT-PCR analysis of the KCNQ1 expression in human pancreatic organoids of UC, and KCNQ1 R397W $\beta$-like cells. $p$ values calculated by two-way ANOVA.

B. Fold-change of insulin secretion in maturing human $\beta$-like cells (day 28 ) with $30 \mathrm{mM} \mathrm{KCl}$ stimulation between WT and KCNQ1 R397W $\beta$-like cells. 
C, D. Insulin secretion assay (C), and total insulin assay (D) are analyzed with ELISA in mouse

SJ $\beta$ cells untransfected and transfected with expression constructs of KCNQ1WT (wild type)

and KCNQ1R397W.

Data information: Data are presented as mean \pm SD. n.s indicates a non-significant difference,

${ }^{*} p<0.05,{ }^{* *} p<0.01,{ }^{* * *} p<0.001$, and ${ }^{* * * *} p<0.0001$ (Student's t-test). 
A

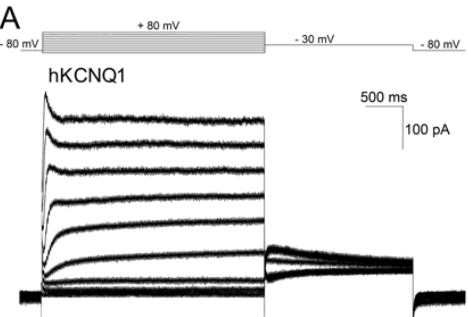

$\frac{1}{2}$
$\frac{0}{a}$
0
$\frac{a}{2}$
$\frac{1}{0}$
$\frac{0}{0}$
$\frac{0}{0}$
$\frac{1}{c}$
0
$\frac{5}{7}$
0

hKCNQ1R397w

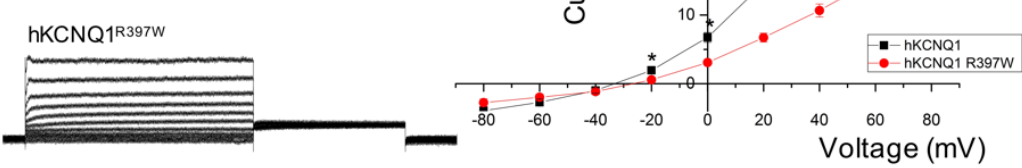

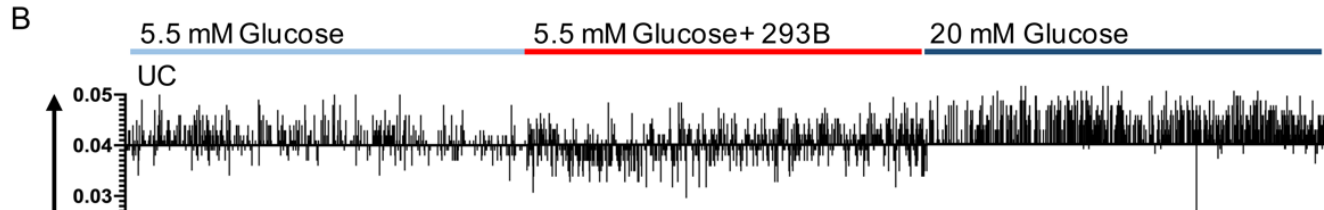

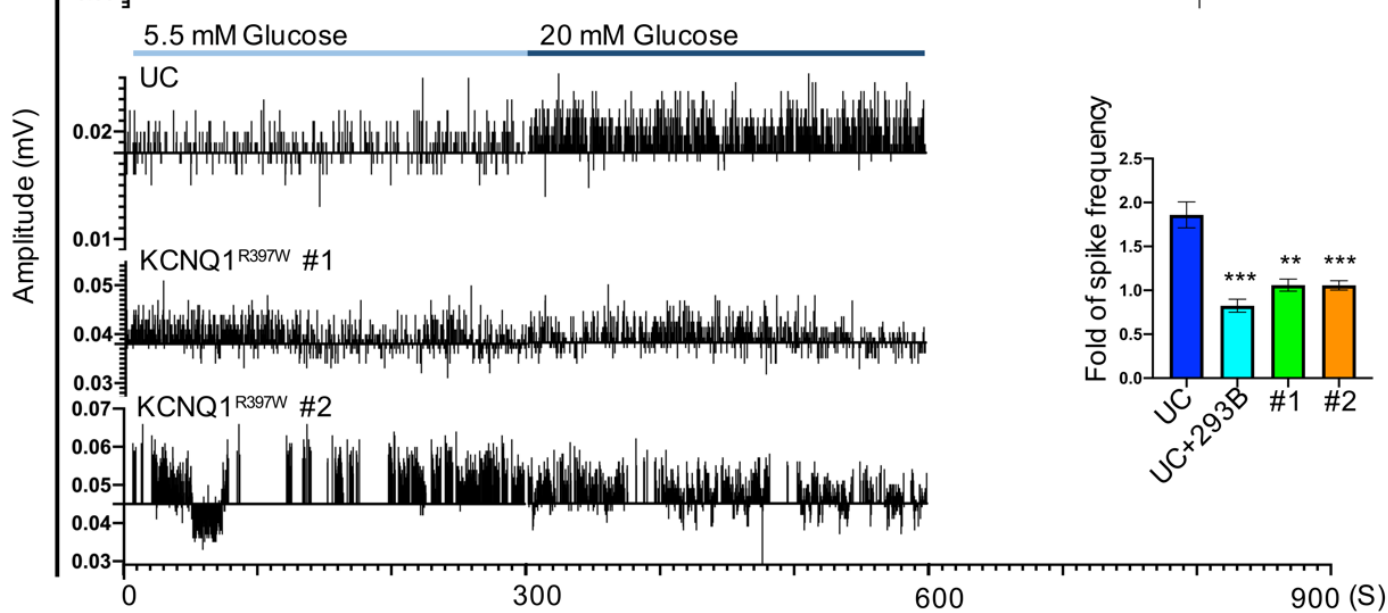

C

$$
\begin{aligned}
& \rightarrow-W T \rightarrow K C N Q 1^{R 397 W} \# 1 \\
& --U C \rightarrow K C N Q 11^{R 397 W} \# 2
\end{aligned}
$$

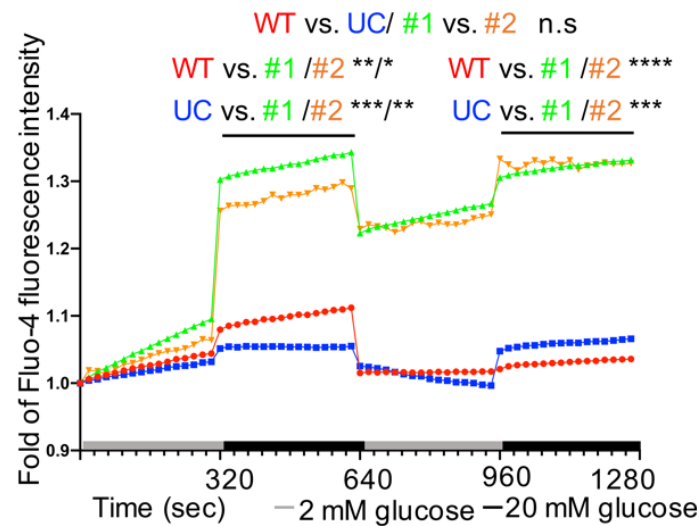

D $\rightarrow-U C$

- KCNQ1 ${ }^{\mathrm{R} 397 \mathrm{~W}} \# 1+293 \mathrm{~B}$

$\rightarrow W T+293 B$

$\rightarrow-U C+293 B$

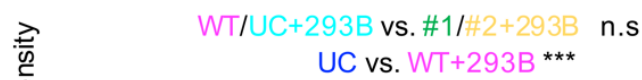

UC vs. $W T+293 B$ ***

UC vs. UC $+293 B$ **

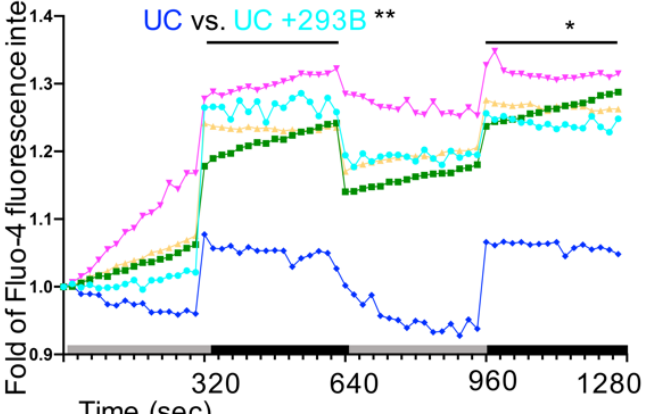


$E$

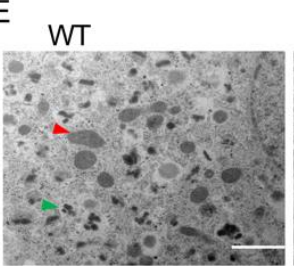

UC

KCNQ1 ${ }^{R 397 W} \# 1$

KCNQ1 ${ }^{R 397 W} \# 2$
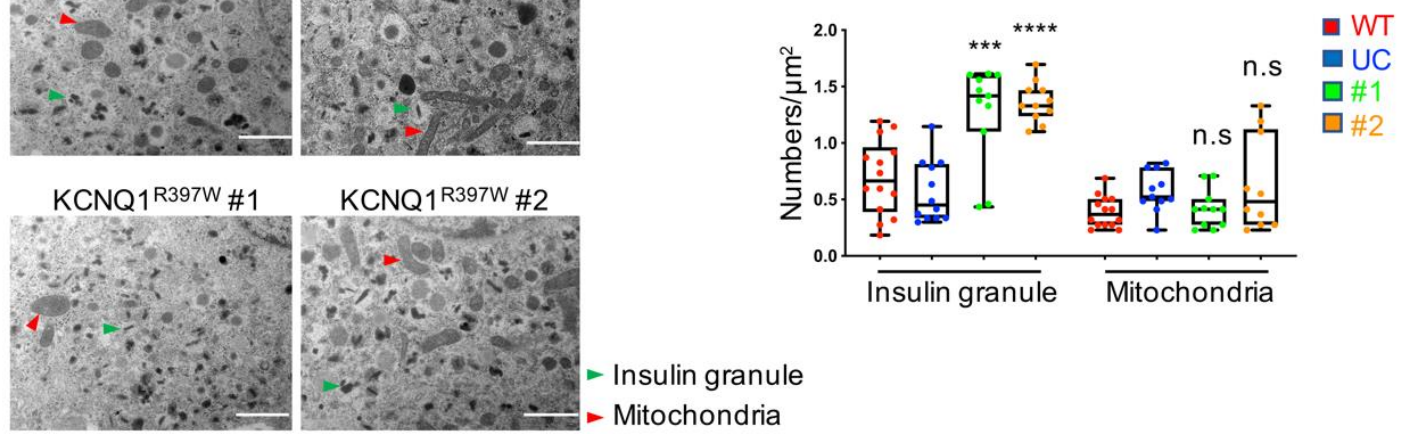

Figure 4. KCNQ1 ${ }^{\mathrm{R} 397 \mathrm{~W}}$ enhances channel activities in $\beta$-like cells that results in a cytoplasmic

\section{$\mathrm{Ca}^{2+}$ accumulation.}

A. Current traces for KCNQ1WT and KCNQ1R397W in transfected KCNQ1-null Chinese Hamster Ovary $(\mathrm{CHO})$ cells (patch clamp). Data presented as mean $\pm \mathrm{SEM}, \mathrm{p}$ values calculated by two-way ANOVA.

B. Recording of electrical activity and quantification of the spike frequency of human mature $\beta$-like cells induced by $5.5 \mathrm{mM}$ glucose with/without $10 \mu \mathrm{M}$ Chromanol 293B (293B) and 20 $\mathrm{mM}$ glucose. Data presented as mean \pm SD (Student's t-test).

C, D. The dynamic $\mathrm{Ca}^{2+}$ flux analysis of $\beta$-like cells by Fluo-4 AM staining. $\beta$-like cells were cultured with (D) or without Chromanol 293B (293B) (C). Data presented as mean; $p$ values calculated by two-way ANOVA.

E. Electron microscopy images and quantification of the crystallized insulin granules (green arrows) and mitochondria (red arrows). Scale bar $=1 \mu \mathrm{m}$. Data presented as mean \pm SD (Student's t-test).

Data information: n.s indicates a non-significant difference, ${ }^{*} p<0.05,{ }^{* *} p<0.01,{ }^{* * *} p<0.001$, and ${ }^{* * * *} p<0.0001$ 
bioRxiv preprint doi: https://doi org/10.1101/2021 08 24 457485; this version posted August 26, 2021. The copyright holder for this preprint (which was not certified by peer review) is the author/funder, who has granted bioRxiv a license to display the preprint in perpetuity. It is made available under aCC-BY-NC-ND 4.0 International license.

A

HUMan SSTWKIY IRKAPRSHTLLS

Rhesus SSTWKIYVRKPSRSHALLS

Mouse SATWKIYVRKPARSHTLLS

Dog SSTWKIYVRKPARSHALLS

Elephant SSTWKIYVRKPARNHTLLS X_tropicalis SATWKIY IRKQSRNHHILS

C

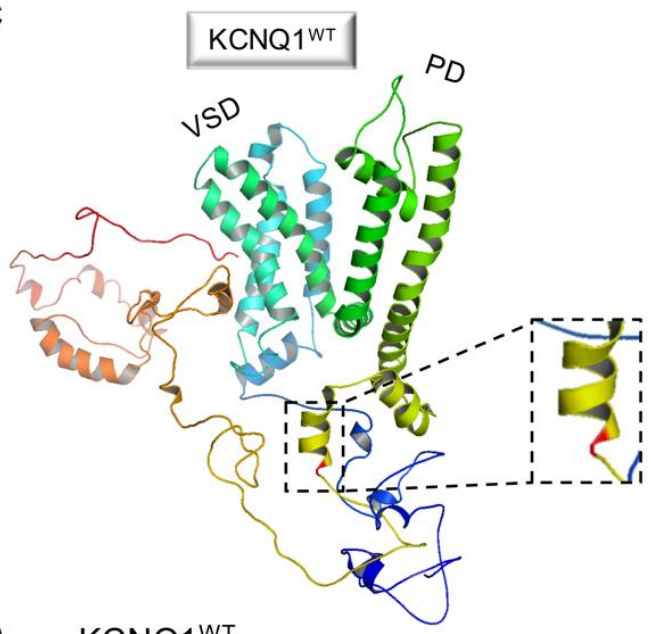

D
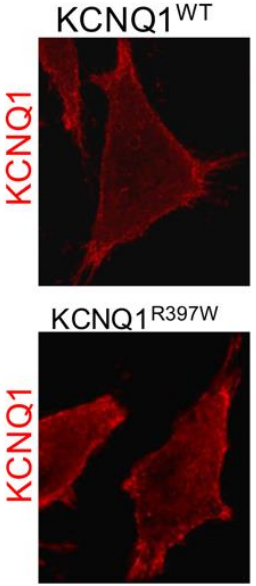

$\mathrm{F}$

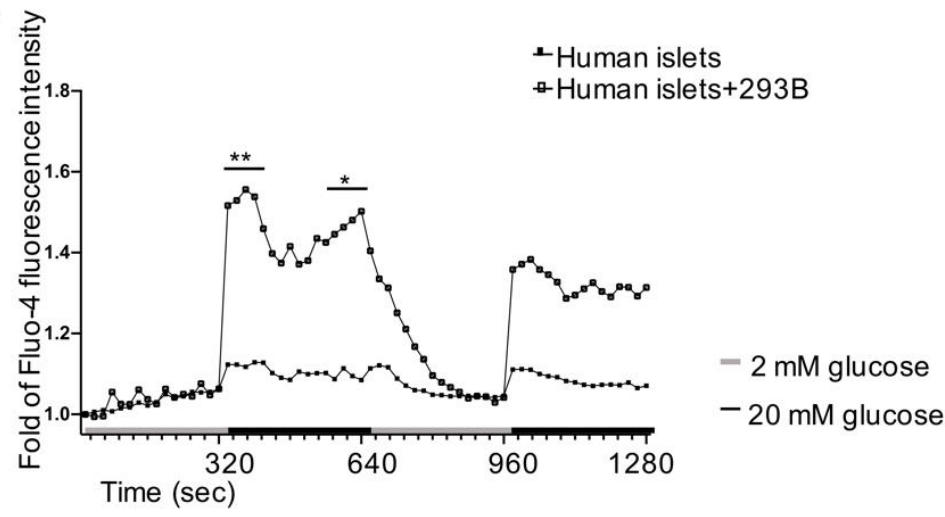

Human islets

- Human islets+293B
B

Socre: 0.918 (sensitivity: 0.68 ; specificity: 0.90 )
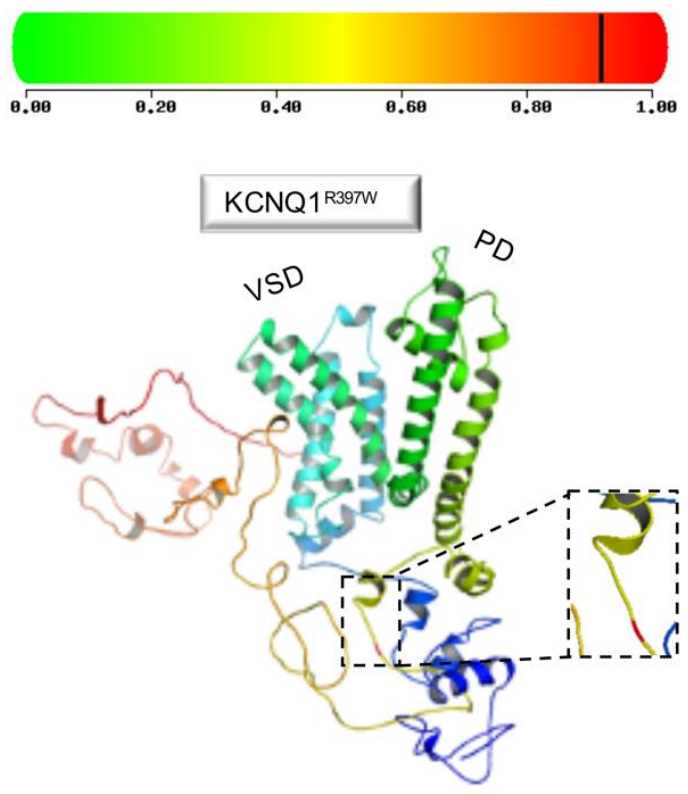

UC KCNQ1 $1{ }^{R 397 W ~ \# 1 ~ K C N Q 1 R 397 W ~ \# 2 ~}$

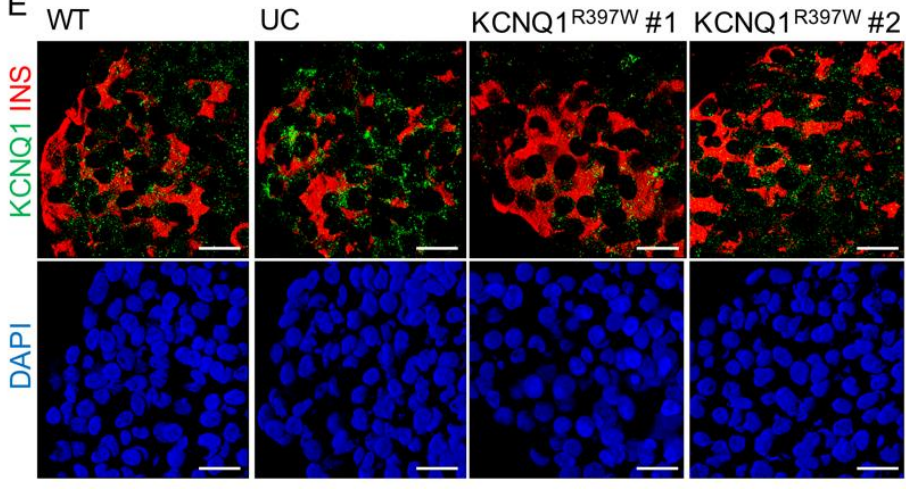

Figure EV4. Function prediction of KCNQ1R397w.

A. Amino acid sequence around the mutation (red) is conserved in KCNQ1. 
B. Polyphen2 prediction for the destructive potential of the R397W mutation in KCNQ1.

C. 3D structure prediction of KCNQ1 ${ }^{W T}$ and KCNQ1 ${ }^{\mathrm{R} 397 \mathrm{~W}}$. The figures are generated using the PyMOL viewer. Left panel, KCNQ1WT with the mutation locus (highlighted in red) is located in an $\alpha$ helix. Right panel, KCNQ1R397w, the mutation disrupts the helical structure. Instead of an $\alpha$ helix, a random coil is predicted (The mutation is highlighted in red).

D. Immunostaining for KCNQ1 ${ }^{\mathrm{WT}}$ and KCNQ1 ${ }^{\mathrm{R} 397 \mathrm{~W}}$ expressed in KCNQ1-null Chinese hamster ovary $(\mathrm{CHO})$ cells (red).

E. Immunostaining of insulin (red) and KCNQ1 (green) in human $\beta$-like cells (day 31) shown by 3D confocal scanning. Scale bar=20 $\mu \mathrm{m}$.

F. The dynamic $\mathrm{Ca}^{2+}$ flux of human $\beta$-cells by Fluo-4 AM staining. Human islets were cultured with or without Chromanol 293B (293B). Data are presented as mean. p values are calculated by two-way ANOVA. n.s indicates a non-significant difference, ${ }^{*} p<0.05,{ }^{* *} p<0.01,{ }^{* * *} p<$ 0.001 , and ${ }^{* * * *} p<0.0001$. 
A

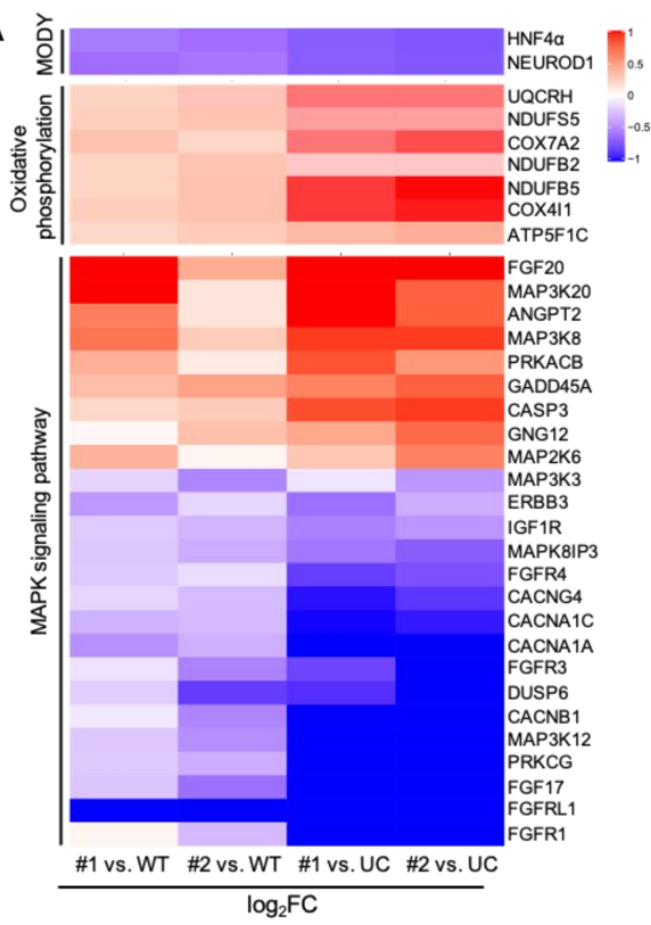

D

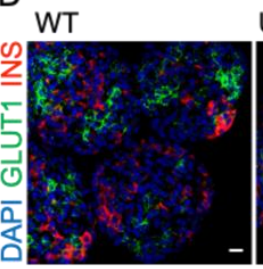

UC
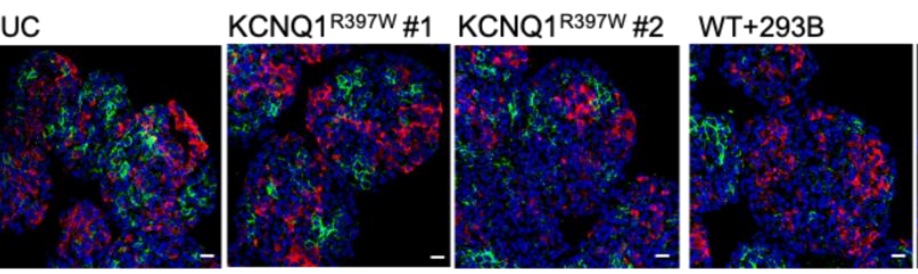

UC+293B
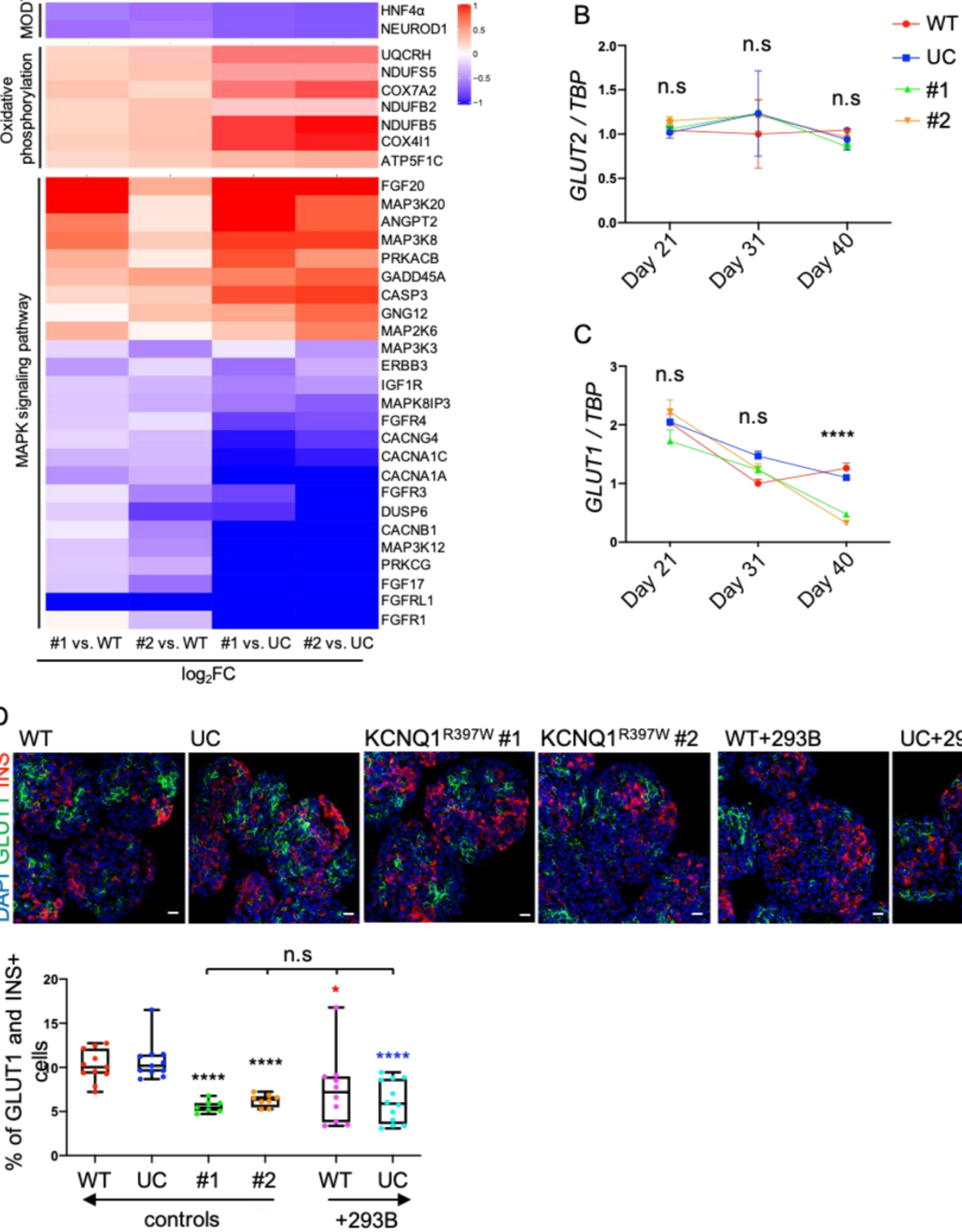

Figure 5. The KCNQ1 ${ }^{\mathrm{R} 397 \mathrm{~W}}$ mutation results in a reduced glucose transport of $\beta$-like cells at

their late stage.

A. Heat map showing the differentially expressed genes (DEGs) revealed by RNAseq

analysis. The DEGs belong to the GO categories of $M O D Y$, oxidative phosphorylation and

\section{MAPK signaling.}

B, C. Expression qRT-PCR analyses of GLUT2(B) and GLUT1(C) in stage-specific

pancreatic organoids of WT, UC, and KCNQ1 $3397 \mathrm{~W}$. Data are normalized to TBP. 
D. Immunoassaying of GLUT1 (green) and insulin (INS, red) positive cells in late mature $\beta$-like cells (day 40), cultured in normal S7 media (control) or S7 media supplemented with chromanol 293B (+293B) for 12 days (from day 28 to day 40). The INS+/GLUT1+ cells were quantified. Scale bar $=20 \mu \mathrm{m}$.

Data information: The data are presented as mean \pm SD. Two-way ANOVA (B and C) or Student's t-test (D). n.s indicates a non-significant difference, ${ }^{*} p<0.05,{ }^{* *} p<0.01,{ }^{* * *} p<$ 0.001 , and ${ }^{* * *} \mathrm{p}<0.0001$. 
bioRxiv preprint doi: https://doi.org/10.1101/2021.08 24 457485; this version posted August 26, 2021. The copyright holder for this preprint (which was not certified by peer review) is the author/funder, who has granted bioRxiv a license to display the preprint in perpetuity. It is made available under aCC-BY-NC-ND 4.0 International license.

A

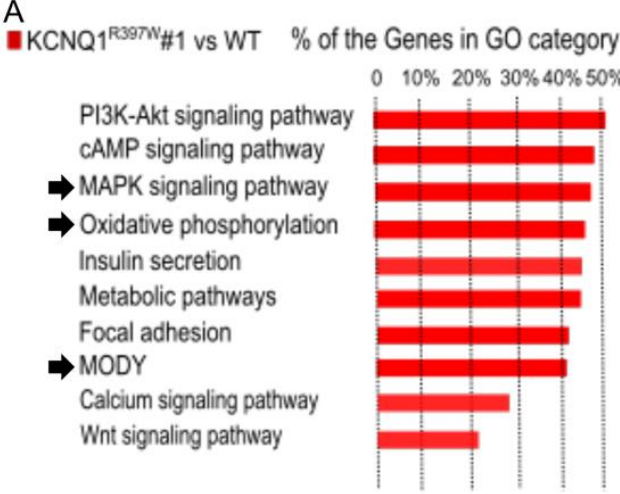

$\| K C N Q 1^{1397 v} \# 1$ vs UC $\%$ of the Genes in GO category

$10 \% 20 \% 30 \% 40 \% 50 \%$

$\Rightarrow$ Oxidative phosphorylation CAMP signaling pathway Metabolic pathways PI3K-Akt Pathway PPAR signaling pathway

\section{$\Rightarrow$ MODY}

Insulin resistance

Insulin secretion

Type II diabetes mellitus

$\Rightarrow$ MAPK signaling pathway

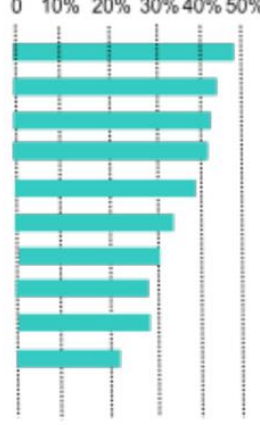

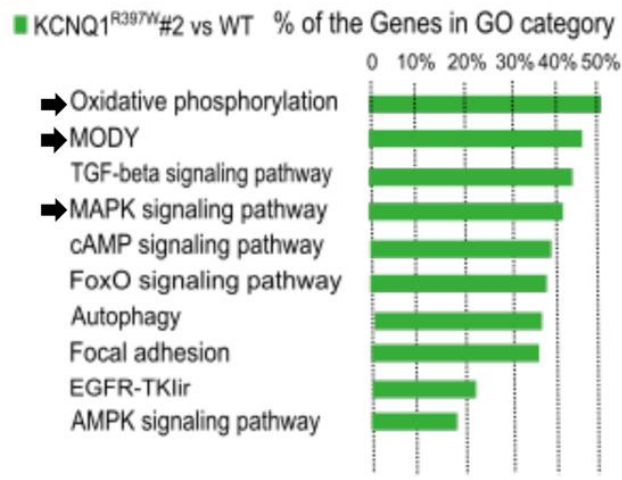

- KCNQ1 ${ }^{\text {R397W } \# 2 ~ v s ~ U C ~} \%$ of the Genes in GO category

$\Rightarrow$ Oxidative phosphorylation mTOR signaling pathway TGF-beta signaling pathway Autophagy

$\Rightarrow$ MAPK signaling pathway cAMP signaling pathway $\Rightarrow M O D Y$

AMPK signaling pathway EGFR-TKlir

FoxO signaling pathway
0 $10 \% 20 \% 30 \% 40 \% 50 \%$

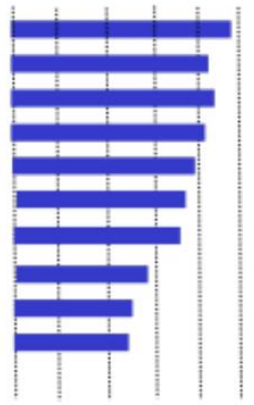

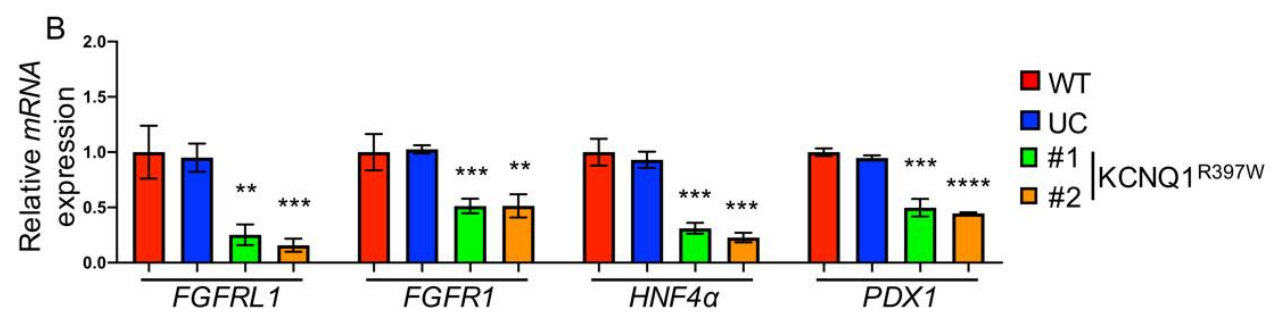

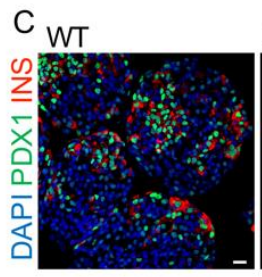

UC

KCNQ1 ${ }^{\mathrm{R} 397 W}$ \#1 KCNQ1 R397W \#2
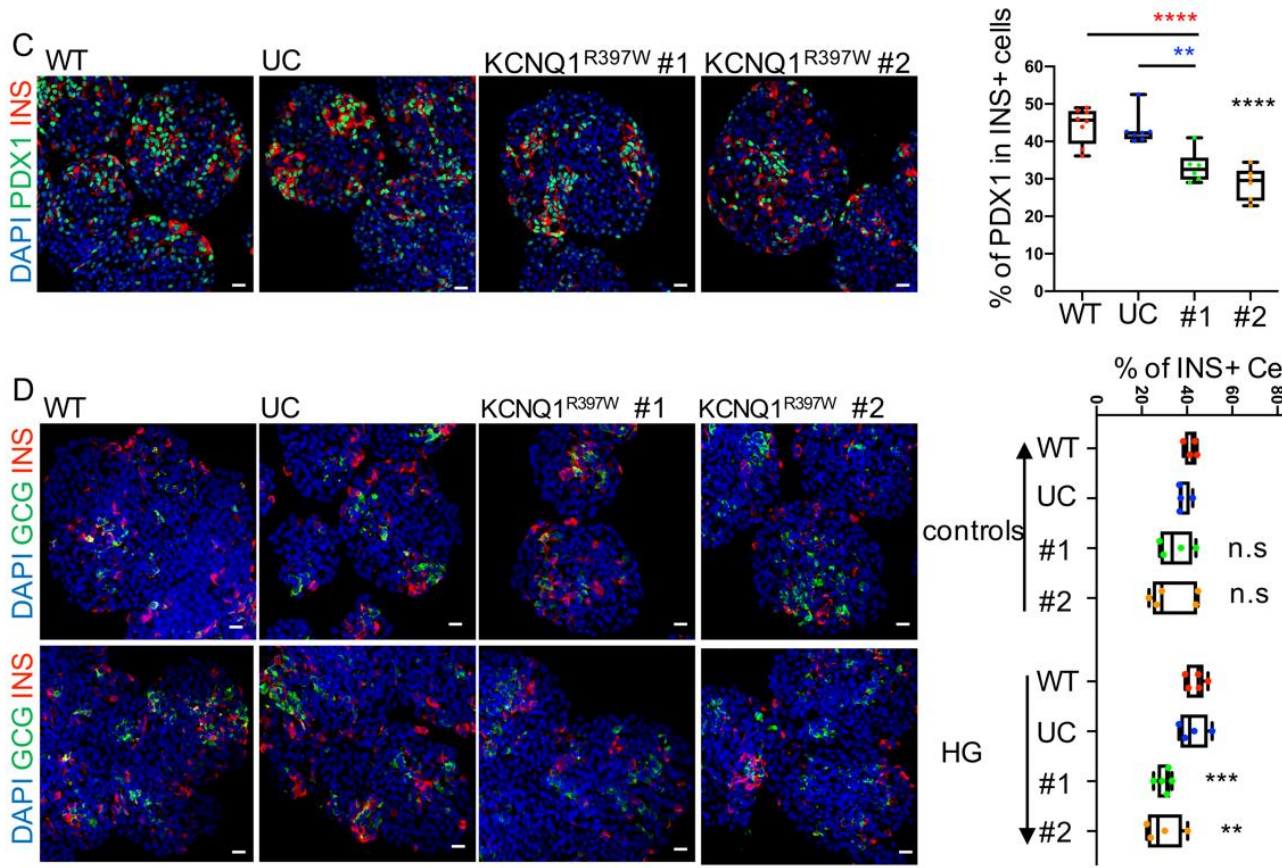

UC

$\mathrm{KCNQ}^{\mathrm{R} 397 \mathrm{~W}}$ \#1 KCNQ1 ${ }^{\mathrm{R} 397 \mathrm{~W}}$ \#2

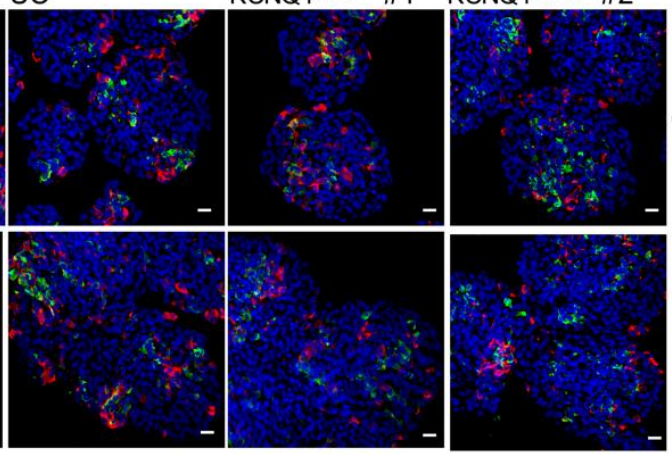

contro

年


Figure EV5. The analysis of differentially expressed genes, and the assay of chronic exposure to high glucose.

A. GO analysis of differentially expressed genes (DEGs). The most significant categories are marked.

B. qRT-PCR analysis of FGFRL1, FGFR1, HNF4a and PDX1 expression in WT, UC, and KCNQ1R397W $\beta$-like cells at their late stage (day 40). Data are normalized to $T B P$.

C. Late-stage $\beta$-like cells were immunoassayed for PDX1 (green) and insulin (INS, red), and quantified.

D. Late stage $\beta$-like cells were cultured in normal media (controls) or in media supplemented with $20 \mathrm{mM}$ glucose (high glucose, HG), immunoassayed for glucagon (GCG, green) and insulin (INS, red), and quantified.

Data information: Scale bar $=20 \mu \mathrm{m}(C$ and $D)$. In $(B-D)$, the data are presented as mean $\pm S D$; n.s indicates a non-significant difference, ${ }^{*} p<0.05,{ }^{* *} p<0.01,{ }^{* * *} p<0.001$, and ${ }^{* * * *} p<$ 0.0001 (Student's t-test). 

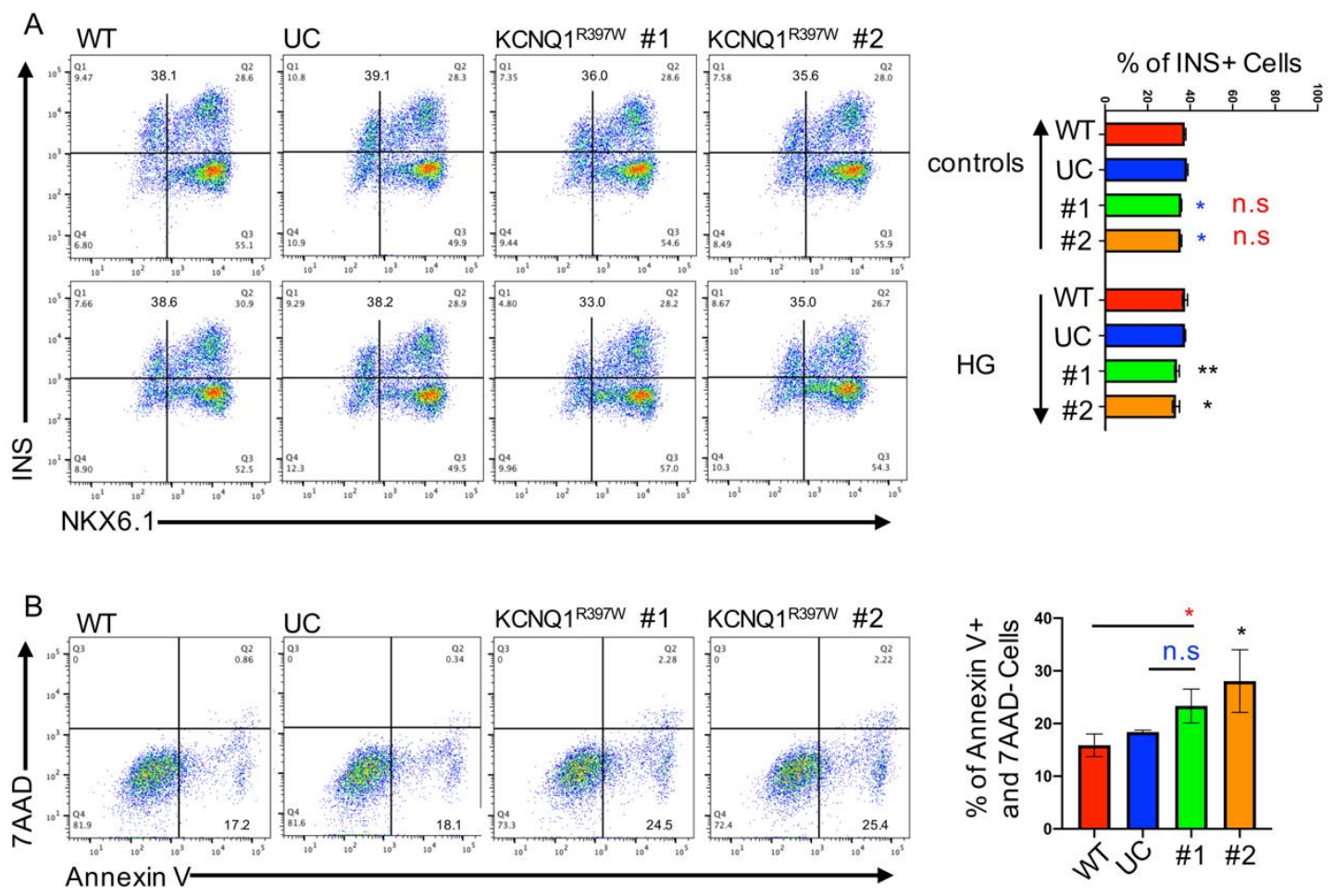

Figure 6. Late-stage KCNQ1 R397W $\beta$-like cultures harbor pro-apoptotic cells.

A. Flow cytometry analysis and quantification of insulin expressing $\beta$-like cells. Matured $\beta$-like cells were cultured in normal S7 media (controls) or in S7 media supplemented with $20 \mathrm{mM}$ glucose (high glucose, HG) for 9 days (from day 32 to day 40), and subjected to flow cytometry. B. Flow cytometry analysis and quantification of the pro-apoptotic (Annexin V+/7AAD-) cells in late mature $\beta$-like cultures.

Data information: The data are presented as mean \pm SD; n.s indicates a non-significant difference, ${ }^{*} p<0.05,{ }^{* *} p<0.01,{ }^{* * *} p<0.001$, and ${ }^{* * *} p<0.0001$ (Student's t-test). 
Table S1: KCNQ1 primers for mutation confirmation, mutagenesis, and construct screening

\begin{tabular}{|c|c|c|c|}
\hline Name & Forward primer(5'to3') & Reverser primer ( $5^{\prime}$ to $\left.3^{\prime}\right)$ & $\begin{array}{l}\text { Product } \\
\text { (bps) }\end{array}$ \\
\hline Exon9 & ССTTCCTGGGCACATACA & AGCCAACCACGTCCACT & 682 \\
\hline R397W & $\begin{array}{l}\text { CCACCTGGAAGATCTACA } \\
\text { TCTGGAAGGCCCCCCGGA } \\
\text { GCCACA }\end{array}$ & $\begin{array}{l}\text { TGTGGCTCCGGGGGGCCT } \\
\text { TCCAGATGTAGATCTTCCA } \\
\text { GGTGG }\end{array}$ & \\
\hline Kcnq1_S1 & $\begin{array}{l}\text { ACATCAATGGGCGTGGAT } \\
\text { AG }\end{array}$ & $\begin{array}{l}\text { GAAGACGGCGAAGTGGTA } \\
\text { AA }\end{array}$ & 580 \\
\hline Kcnq1_S2 & GGCCTGGCCAAGAAGTG & $\begin{array}{l}\text { GGTACACAAAGTACGAGG } \\
\text { AGAAG }\end{array}$ & 760 \\
\hline Kcnq1_S3 & CCGCCAGGAGCTGATAAC & $\begin{array}{l}\text { TTCTTTACCACCACAGACT } \\
\text { TCTT }\end{array}$ & 486 \\
\hline Kcnq1_S4 & TGCTATGCTGCCGAGAAC & $\begin{array}{l}\text { CCTTGTCTTCTACTCGGTT } \\
\text { CAG }\end{array}$ & 655 \\
\hline Kcnq1_S5 & $\begin{array}{l}\text { GAAGCCCTCACTGTTCAT } \\
\text { CT }\end{array}$ & TCAGGACCCCTCATCGGG & 328 \\
\hline
\end{tabular}

S: screening 
Table S2: The sequence of gRNA and ssDNA for gene editing.

\begin{tabular}{|c|c|c|}
\hline Name & Usage & Sequence (5'-3') \\
\hline KCNQ1g-1 & $\begin{array}{l}\text { sgRNA+Bpil } \\
\text { sticky end }\end{array}$ & $\begin{array}{l}\text { Forward: CACCGCCCGACCTCAGACCGCATGG } \\
\text { Reverse: AAACCCATGCGGTCTGAGGTCGGGC }\end{array}$ \\
\hline KCNQ1g-2 & $\begin{array}{l}\text { sgRNA+Bpil } \\
\text { sticky end }\end{array}$ & $\begin{array}{l}\text { Forward: CACCGCCACCTGGAAGATCTACATC } \\
\text { Reverse: AAACGATGTAGATCTTCCAGGTGGC }\end{array}$ \\
\hline KCNQ1t-1 & ssDNA & $\begin{array}{l}\text { CTGGGTGACAGCAGAGTGTGGCTCCGGGGGGCC } \\
\text { TTCCGGATGTAGATCTTCCAGGTGGAGGAGTCGG } \\
\text { GGTTCTCGGCAGCATAGCATCTCCATGCGGTCTG } \\
\text { AGGTCGGGCAGGGGGACAGGCTGTCAC }\end{array}$ \\
\hline KCNQ1t-2 & ssDNA & $\begin{array}{l}\text { GCCCTGGTGGCAGGTGGGCTACTCACCACCACA } \\
\text { GACTTCTTGGGTTTGGGGCTGGGTGACAGCAGAG } \\
\text { TGTGGCTCCGGGGGGCCTTTCGGATGTAGATCTT } \\
\text { CCAGGTGGAGGAGTCGGGGTTCTCGGC }\end{array}$ \\
\hline
\end{tabular}


Table 3: PCR and qPCR primers

\begin{tabular}{|c|c|c|}
\hline Name & Usage & Sequence $\left(5^{\prime}-3^{\prime}\right)$ \\
\hline KCNQ1 & PCR & $\begin{array}{l}\text { Forward: CTGGCTCAGGGCTGGTAAAG } \\
\text { Reverse: GGAACCTAGCATCGGGTGTA }\end{array}$ \\
\hline Bis-KCNQ1 & $\begin{array}{l}\text { Bisufite } \\
\text { sequencing } \\
\text { PCR }\end{array}$ & $\begin{array}{l}\text { Forward: GGAGTTGGGATTATGTTAAGTTTGT } \\
\text { Reverse: AAAACCCTCTAAAAAACCTTCTTTC }\end{array}$ \\
\hline KCNQ1 & Real-Time PCR & $\begin{array}{l}\text { Forward: CATCACCCACATCTCACAGC } \\
\text { Reverse: GTCCCGCACATCGTAAGG }\end{array}$ \\
\hline KCNQ1ot1 & Real-Time PCR & $\begin{array}{l}\text { Forward: CTTTGCAGCAACCTCCTTGT } \\
\text { Reverse: TGGGGTGAGGGATCTGAA }\end{array}$ \\
\hline SLC22A18 & Real-Time PCR & $\begin{array}{l}\text { Forward: CATCTTGCTTACCTACGTGCTG } \\
\text { Reverse: CCCAGTTTCCGAGACAGGTA }\end{array}$ \\
\hline PHLDA2 & Real-Time PCR & $\begin{array}{l}\text { Forward: TCCAGCTATGGAAGAAGAAGC } \\
\text { Reverse: GTGGTGACGATGGTGAAGTACA }\end{array}$ \\
\hline CDKN1C & Real-Time PCR & $\begin{array}{l}\text { Forward: AGATCAGCGCCTGAGAAGTCGT } \\
\text { Reverse: TCGGGGCTCTTTGGGCTCTAAA }\end{array}$ \\
\hline NANOG & Real-Time PCR & $\begin{array}{l}\text { Forward: CCAAAGGCAAACAACCCACTT } \\
\text { Reverse: CGGGACCTTGTCTTCCTTTTT }\end{array}$ \\
\hline OCT4 & Real-Time PCR & $\begin{array}{l}\text { Forward: CGACCATCTGCCGCTTTG } \\
\text { Reverse: GCCGCAGCTTACACATGTTCT }\end{array}$ \\
\hline Sox2 & Real-Time PCR & $\begin{array}{l}\text { Forward: ACAGCAAATGACAGCTGCAAA } \\
\text { Reverse: TCGGCATCGCGGTTTTT }\end{array}$ \\
\hline Insulin & Real-Time PCR & $\begin{array}{l}\text { Forward: AGCCTTTGTGAACCACACC } \\
\text { Reverse: GCTGGTAGAGGGAGCAGATG }\end{array}$ \\
\hline FGFRL1 & Real-Time PCR & Forward: CCTGAGCGTCAACTACACC \\
\hline
\end{tabular}



made available under aCC-BY-NC-ND 4.0 International license.

\begin{tabular}{|l|l|l|}
\hline & & Reverse: CTCATCTTGGAGGGCTGTG \\
\hline FGFR1 & Real-Time PCR & Forward: AACCTGACCACAGAATTGGAGGCT \\
\hline FGFR3 & Real-Time PCR & Forward: AGGTGAATGGCAGCAAGGT \\
& Real-Time PCR & Forward: AAGTCTACCAAAGCTCACGCG \\
\hline GLUT1 & Real-Time PCR & Forward: TCCCTGCAGTTTGGCTACA \\
& & Reverse: GTGGACCCATGTCTGGTTGT \\
\hline GLUT2 & Real-Time PCR & Forward: CACCAATTCCAGCTACCGAC \\
& & Reverse: CCGTCTGAAAAATGCTGGTT \\
\hline HNF4a & Real-Time PCR & Forward: GAGGAAGGCGAGATTTCCCAG \\
& & Reverse: GAACCATCAGCATGTCTGCG \\
\hline
\end{tabular}


Table S4: Antibodies for flow cytometry and immunofluorescence analysis

\begin{tabular}{|c|c|}
\hline PE Mouse anti-Human Sox17 & BD Biosciences \\
\hline Alexa Fluor® 488 Mouse anti-PDX-1 & BD Biosciences \\
\hline PE Mouse Anti-Nkx6.1 & BD Biosciences \\
\hline Alexa Fluor® 647 Mouse Anti-Nkx6.1 & BD Biosciences \\
\hline $\begin{array}{l}\text { Insulin (C27C9) Rabbit mAb (Alexa Fluor® } 488 \\
\text { Conjugate) }\end{array}$ & Cell Signaling Technology \\
\hline APC anti-Human CD26 & Biolegend \\
\hline PE Mouse Anti-Human CD49a & BD Biosciences \\
\hline Anti-Tra-1-60-PE, human & MACS Miltenyi Biotec \\
\hline Alexa Fluor® 647 Mouse IgG1 k Isotype Control & BD Biosciences \\
\hline FITC Mouse IgG2a, k Isotype Control & BD Biosciences \\
\hline PE Mouse IgG1, k Isotype Control & BD Biosciences \\
\hline APC Mouse IgG2a, $\mathrm{K}$ Isotype Control & Biolegend \\
\hline $\begin{array}{l}\text { Rabbit IgG Isotype Control (Alexa Fluor }{ }^{\circledR} 488 \\
\text { Conjugate) }\end{array}$ & Cell Signaling Technology \\
\hline FITC Annexin V & BD Biosciences \\
\hline PDX1 Mouse Monoclonal Antibody & Origene \\
\hline Homeobox protein Nkx-6.1 & Developmental Studies \\
\hline Purified Mouse Anti-Ki-67 & BD Biosciences \\
\hline
\end{tabular}




\begin{tabular}{|c|c|}
\hline Anti-KCNQ1 antibody & ATLAS ANTIBODIES \\
\hline FLEX Polyclonal Guinea Pig Anti-Insulin Ready-to-use & Agilent \\
\hline Insulin (C27C9) Rabbit mAb & Cell signaling Technology \\
\hline Monoclonal Anti-Glucagon antibody & Sigma \\
\hline C-Peptide Antibody & Cell signaling Technology \\
\hline Sox2 (L1D6A2) Mouse mAb & Cell signaling Technology \\
\hline Oct-4 Antibody & Cell signaling Technology \\
\hline Actin, pan Ab-5 & Dianova \\
\hline Alexa Fluor TM 488 Goat Anti-Mouse & Invitroge \\
\hline $\begin{array}{l}\text { Goat anti-Rabbit IgG }(\mathrm{H}+\mathrm{L}) \text { Highly Cross-Adsorbed } \\
\text { Secondary Antibody, Alexa Fluor } 555\end{array}$ & ThermoFisher \\
\hline $\begin{array}{l}\text { Goat anti-Guinea Pig IgG }(\mathrm{H}+\mathrm{L}) \text { Highly } \\
\text { Cross-Adsorbed Secondary antibody, Alexa Fluor } 647\end{array}$ & ThermoFisher \\
\hline HPR-Anti Rabbit lgG (H+L) & Thermo Scientific \\
\hline HPR-Anti Mouse lgG $(\mathrm{H}+\mathrm{L})$ & Thermo Scientific \\
\hline
\end{tabular}

